\title{
Developing a System Dynamics Model for the Nizhniy Kaban and Sredniy Kaban Lakes, Kazan, Russia, Assessing the Impacts of Phosphorus and Nitrogen Inputs on Lake Ecology
}

\author{
Liudmila L. Frolova • Antoniy Elias Sverdrup • \\ Harald Ulrik Sverdrup (D)
}

Received: 27 February 2020 / Accepted: 30 September 2021 / Published online: 30 October 2021

(C) The Author(s) 2021

\begin{abstract}
The Kaban Lakes Integrated Assessment Model (KLIAM) was developed for the lake hydrology, chemistry, and plankton dynamics of the Nizhniy Kaban and Sredniy Kaban lakes, Kazan, Russia. KLIAM is able to describe the variations seen in the Kaban lakes chemical and biological states as far seen through measurements available at the moment. KLIAM is able to reconstruct the lake history as it is approximately known from the data and written narratives. KLIAM was used to assess the measures to return the lakes to their original pre-urban status as alkaline and semi-oligotrophic lakes. The Kaban Lakes periodically goes through plankton blooms, as seen in the lake in the last decades since before World War II, which are caused by plankton growth promoted by phosphorus and nitrogen coming to the lakes as pollution from the human environment. In the new plans for development of the area surrounding the Nizhniy Kaban and Sredniy Kaban lakes, we suggest that attention is paid to reducing phosphorus and nitrogen flows to the lakes, as the best way to improve their ecological status. This is based on
\end{abstract}

L. L. Frolova · A. E. Sverdrup

Genetics and Bioinformatics, Kazan Federal University,

Kremlevskaya Street 18, Kazan RU-420 008, Russia

H. U. Sverdrup ( $\bowtie)$

Department of Gamification and Interactive Simulations,

Game School, Inland Norway University of Applied

Sciences, Holsetgaten 31, NO-2318 Hamar, Norway

e-mail: harald.sverdrup@inn.no simulations with KLIAM. We recommend that the monitoring of lake chemistry and lake ecology is improved with reoccurring analysis of samples from the Kaban Lakes.

Keywords System dynamics · Supply ·

Sustainability · Kaban Lakes · Eutrophication ·

Phosphorus $\cdot$ Nitrogen

\section{Introduction}

The Kaban Lakes are located within the city limits of Kazan, Russia, and are the largest lakes in the Tatarstan Republic (Figs. 1, 2, 3). They are important parts of the city landscape and important resource for the recreation resources of the city. They are located in a pleasant environment, and a redevelopment of the area surrounding the lakes is planned for the next decade. The lakes are exposed to the activity of the city and in the past, this meant that a lot of city pollution reached the lakes. They became the target for dumping all kinds of waste (Kalimullin, 2005; Kalimullin \& Vinogradov, 2015; Klaus, 1839; Vishlenkova, 2005).

The lakes have been eutrophic and polluted for a long time because of industrial and domestic sewage flowing freely from the city to the lakes (Klaus 1833, Vishlenkova, 2005; Kalimullin, 2005; Kalimullin \& Vinogradov, 2015). 
Fig. 1 The Nizhniy Kaban Lake seen towards the Kazan city centre around the year 2000. Note that the water is greenish due to a high concentration of plankton and algae in the water
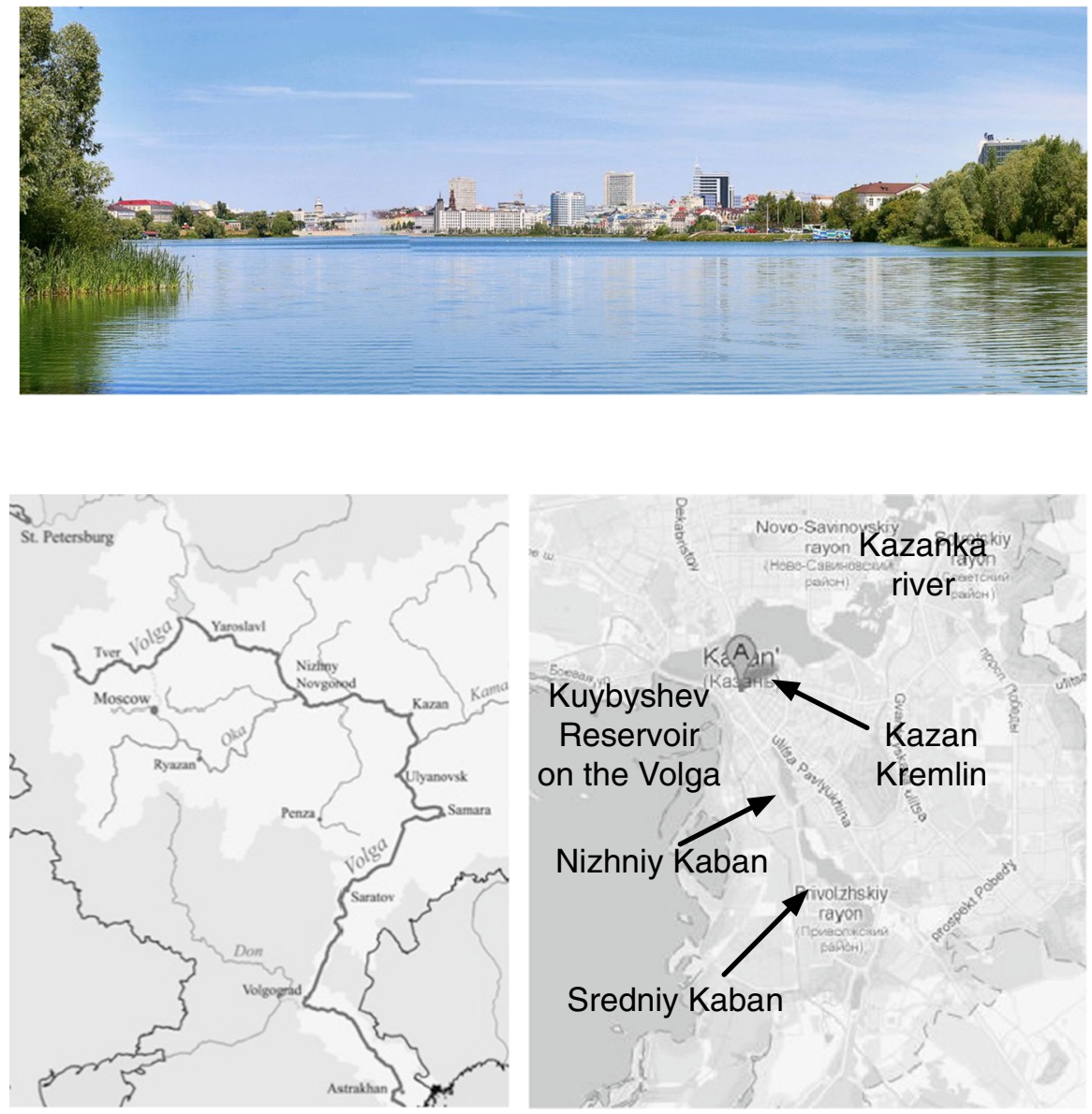

Fig. 2 The location of Kazan City on the Volga River in Russia and the location of the Kaban Lakes within the city of Kazan. The lakes are located inside the metropolitan area
It was known that waters in Kazan were not suitable for drinking because of all the pollution in the city and from the city to the lakes, contaminating drinking water wells and the Kaban Lakes (Kupidonov, 1890, Vishlenkova, 2005). It started with the establishment of industries already around 1840 (Filtzer, 2008; Kalimullin \& Vinogradov, 2015; Krestovnikov, 1870). These were in the beginning meat and dairy processing industries, discharging raw sewage straight to the lakes. Later, chemical industries, textile mills, tanneries and soap factories were established around the lake. By 1850, the lakes were already heavily polluted (Kalimullin \& Vinogradov, 2015). During the communist dictatorship, further urban sewage was channelled to the lakes (Filtzer, 2008). The lakes still suffers from this past pollution history, and more professional efforts are needed to improve the water quality of the lakes, such as making swimming and bathing a pleasant experience. From 1981, the Kaban Lakes recovery committee started working
(Derevenskaya et al., 2015; Mingazova, 1999; Mingazova et al., 2019).

Table 1 shows some data describing the lakes. The lakes are frozen over by ice from December to the end of March. The lakes experience a typical continental climate, with warm summers $\left(20\right.$ to $30{ }^{\circ} \mathrm{C}$ ) and cold winters $\left(-10\right.$ to $\left.-30{ }^{\circ} \mathrm{C}\right)$. Figure 1 shows the Nizhniy Kaban Lake seen towards the Kazan city center. The catchments are largely within the city limits, but Sredniy Kaban Lake has some more rural and vegetated parts in the eastern part of the catchment. Figure 2 shows an outline of one of the proposed development plans around the Kaban Lake shorelines. The lake shoreline will be developed during the next decade.

\section{Objectives and Scope}

The objective is to develop an integrated process-oriented model system for the hydrology, chemistry, biology and 


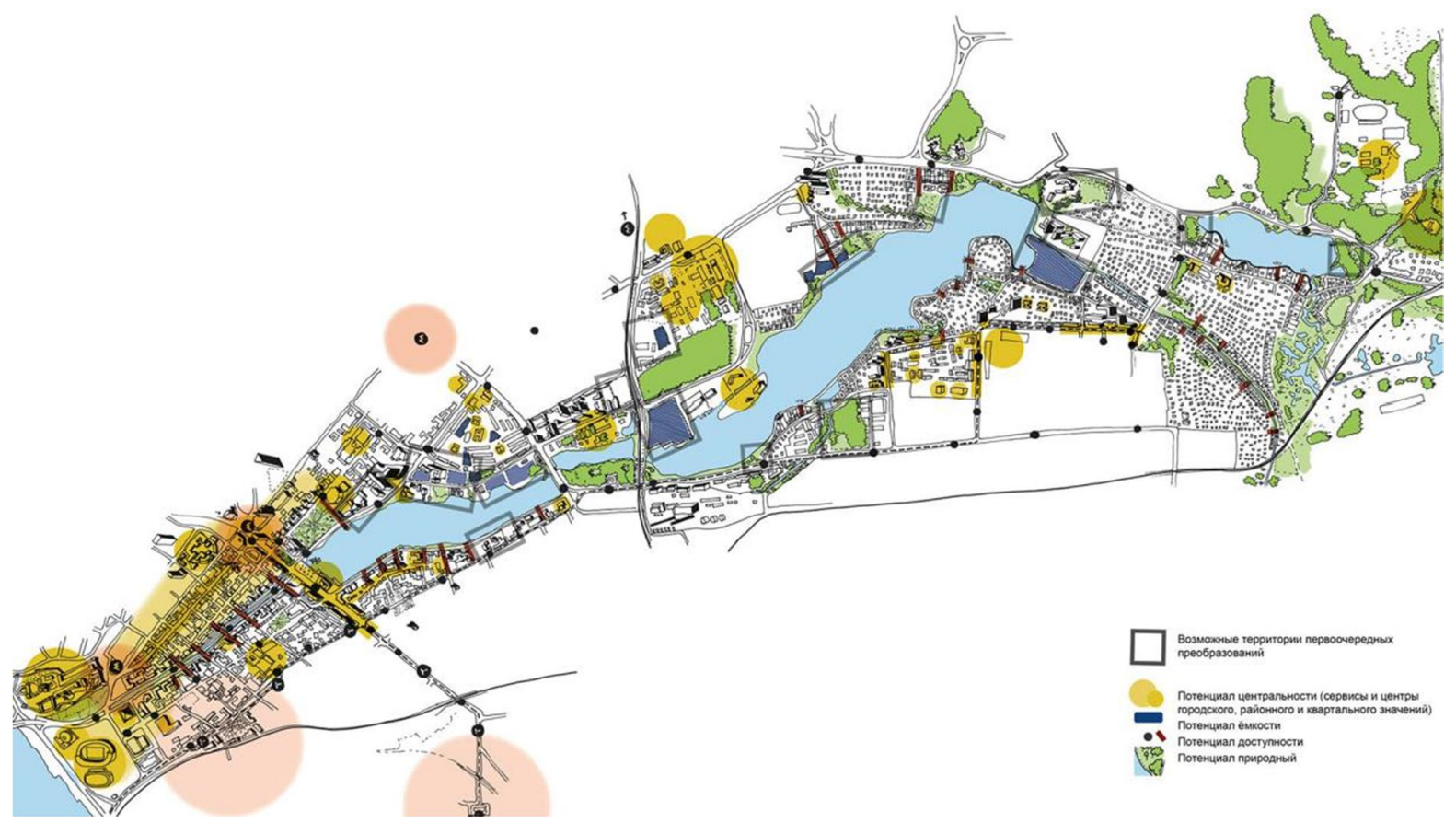

Fig. 3 Outline of one of the proposed development plans around the Kaban Lake shorelines. The lake shoreline will be developed during the next decade for urban recreational use, and the shoreline has been cleaned up and physical redone. Most of the old polluting industries have been removed (Save one on the Sredniy Kaban Lake, but that is also due to move in the future) Nizhniy Kaban Lake is the lake to the left, Sredniy Kaban Lake is the lake to the right in the drawing (Derevenskaya et al., 2015; Mingazova et al., 2019)

values, but note that the sources vary some on the value of the parameters. (a-Data from Gorshkova et al., 2011, b-Kondratieva et al., 2013, c-Urbanova et al., 2012). Subsurface inflow is water moved by pumps in pipes between the lakes

Table 1 Hydrological and physical characteristics of the Kaban Lakes, Kazan, Russia. 1-From the catchment, 2-between the lakes, 3-net water exchange, 4-Bulak catchment input. We assume that these can be used as long-term average

$\begin{array}{lcll}\begin{array}{l}\text { Max depth } \\ \mathrm{m}\end{array} & \begin{array}{l}\text { Inflow }^{\mathrm{a}} \\ \mathrm{mill} \mathrm{m}^{3} \mathrm{yr}^{-1}\end{array} & \begin{array}{l}\text { Lake water } \\ \text { residence time, } \\ \text { years }\end{array} & \text { Catchment, } \mathrm{km}^{2} \\ \begin{array}{l}17.3 \\ 19.0\end{array} & 4.88^{1} & 0.59 & 9.68^{\mathrm{c}} \\ 22.8^{\mathrm{b}} & 24.35^{1, \mathrm{c}} & 0.39 & 38.63^{\mathrm{c}} \\ & & & \\ 4.4 & 4.00^{2} & 0.04 & 1.10 \\ & 1.56^{3} & & \\ & & & \\ 0.8 & 0.63^{4} & 0.03 & 1.30 \\ - & 5.31 & - & - \\ - & 6.95 & - & -\end{array}$

$\begin{array}{lll}\text { Surface area }^{\mathrm{a}} & \text { Lake volume }^{\mathrm{a}} & \text { Average depth } \\ \mathrm{km}^{2} & \text { mill m}^{3} & \mathrm{~m}\end{array}$

Object

$\begin{array}{lll}0.456 & 3.82 & 8.4 \\ 1.200^{\mathrm{b}} & 7.99^{\mathrm{b}} & 7.6 \\ 1.313 & 10.01^{\mathrm{a}} & \\ & 11.56^{\mathrm{c}} & \end{array}$

\section{Channel from \\ Nizhniy lake}

0.064

0.16

2.5

Subsurface inflow

\begin{tabular}{lllc} 
Bulak channel & 0.032 & 0.02 & 0.65 \\
Pump to Kazanka & - & - & - \\
Pump to Volga & - & - & - \\
\hline
\end{tabular}

lake ecosystem quality of the Nizhniy Kaban and Sredniy Kaban lake system. This model will be used to evaluate different aspects of the potential outcomes of the lake management plan and measures to be taken. The Integrated Assessment Model will be designed to have predictive capability, in order to be able to forecast possible 
outcomes of measures taken in the lake catchments (limit nitrogen and phosphorus inputs, potentially remove part of sediments, change input and output flowrates through pumping) and in the lakes themselves. The model should be able to handle short-term variations (within a year) and long-term aspects (100-200 years).

\section{Methods}

The methodology used here uses systems analysis for conceptualization, as the preparation for building a simulation model using the STELLA software. The main standard methods of systems analysis and system dynamics modelling are used (Albin, 1997; Forrester, 1961, 1969, 1971; Meadows et al., 1972, 1974, 1992, 2005; Modin-Edman et al., 2007; Molot \& Dillon, 1993; Roberts et al., 1982; Senge, 1990; Haraldsson \& Sverdrup, 2005; Haraldsson et al., 2008; Haraldsson, 2004; Kim, 1992; Perssson et al., 1999; Sverdrup et al., 2018; ISEE Systems, 2018; Barron et al., 2009; Scheffer, 1990; Ragnarsdottir \& Sverdrup, 2011; Öborn et al., 2005). We analyse the system using stock-and-flow charts and causal loop diagrams. The learning loop is the adaptive learning procedure followed in our studies (Senge, 1990). The entering of the code follows from the causal loop diagrams and flow charts developed in the conceptualization stage.

The model is based on mass balances. The mass balance expressed differential equations resulting from the flow charts, and linkages and feedback as shown in the causal loop diagrams. The differential equations were numerically solved using a 4-step Runge-Kutta algorithm, as implemented in the STELLA® Architect modelling environment. The software was supplied commercially from ISEE Systems Inc, Hannover, New Hampshire, USA (Haraldsson \& Sverdrup, 2005; Sverdrup et al., 2018). To the largest degree, all constants and settings have been based on observed system parameters, in order to eliminate the need for calibration. The modelling methods are the same as in our earlier published papers (Frolova et al., 2020; Sverdrup et al., 2020).

\subsection{Model Description}

\subsubsection{General}

Eutrophication implies that the ecosystem is subjected to a high load of nutrients. The most important nutrients, usually limiting the production in the ecosystem, are nitrogen and phosphorus. Nitrogen is needed for the synthesis of amino acids and phosphorus is needed for the cell energy system, adenosine phosphates (ATP) etc. In freshwater ecosystems, phosphorus is usually the limiting nutrient whereas nitrogen sets the limit for production of biomass in marine ecosystems (Sverdrup et al., 1991; Håkanson \& Peters, 1995; Jørgensen et al., 1990; Håkanson et al., 2003, 2005, 2007, Mameus and Håkanson, 2004). The eutrophication process has a number of negative impacts on the performance of the ecosystem (Chapra \& Reckhow, 1983):

- Eutrophication lowers the aesthetic values of lakes and streams. The resulting abundance of algae makes the water murky and bathing unpleasant.

- Algae blooms can cause the oxygen levels in the hypolimnion to decrease below concentrations where benthic fauna die and fish migrate out of the lake.

- Bloom by cyanobacteria and blue-green algae may make the water toxic.

- Abundance of macrophytes can cause problems in channels and rivers by preventing transport of water and vessels.

- Algae impair the performance of water purification works by clogging the water inlet.

- A shift in the species composition of the algae in the lake might result in production of toxins.

Lakes are commonly divided into different categories depending on their trophic status. Oligotrophic lakes are clear water lakes while eutrophic lakes are murky lakes with a high biomass production. The lakes, which are considered to have an intermediate level of nutrients, are called mesotrophic. It has been discovered that the mesotrophic state is unstable and most likely represents a transition state between oligotrophic and eutrophic conditions (Chapra \& Reckhow, 1983; Håkanson et al., 2003, 2005, 2007; Jørgensen et al., 1990).

\subsubsection{Simplifications and Assumptions}

For a specialized limnologist, it is obvious that the description of the lake ecosystem above is very much simplified both from a structural as well as from a functional point of view. Structural simplifications are 
obvious since there are many different types of species on each trophic level in the ecosystem, in the case of zooplankton and phytoplankton several hundreds. Thus, the approach above show a lumped model where each level represents a number of species with similar, or more correct approximately similar, systemic behaviour. From a functional point of view, this approach is simplified since the real ecosystem has a much more complicated structure of feedback mechanisms than the simplified model above. The trophic levels in the model above have more feedback mechanisms than represented by the mass-balances. An example is the carnivorous fish that prey on planktivore fish, the planktivore fish graze on zooplankton. The zooplankton graze on phytoplankton. This model simplifies all fish into one general fish type and all plankton into one type of general plankton. If the management need should arise, we will be able to divide this into the two types of fish and two types of zooplankton mentioned above (Sverdrup et al., 1991, Barkman \& Sverdrup, 1994, Barkman et al., 1994).

Simplifications are always needed in order to be able to model an ecosystem. In fact, it is theoretically impossible to get information about every single species and its interactions in the food web since ecosystems are very complex. The complexity of ecosystems makes them irreducible systems which results in the fact that it is impossible to observe the system without affecting it. This implies that even if we could study the different interactions between different species in a sophisticated aquarium, we can never be sure that the organisms in the real ecosystem behave in the same way as we do not know if we inhibited an important feed-back mechanism, which might be present in the lake, but not in the experimental aquarium. This fact creates a horizon and a limitation of the quality of the information extractable from an ecosystem. A model can never exactly mirror all details of the real ecosystem, neither is it necessary. Despite the limitation of models, they can provide valuable information on the overall characteristic of an ecosystem's behaviour. We assemble models based on our best knowledge, and linking it. Thus, the model will use our knowledge to recreate the system we want to model. Models are powerful interpretation tools for discovering the knowledge lacking about the ecosystem and which areas need to be investigated more thoroughly in order to get a more comprehensive understanding.

\subsubsection{The Basic Principle for a Lake, Considering Hydrology, Phosphorus and Plankton}

Figure 4 shows the basic principles of the hydrological, chemical and biological dynamics of the system, drawn up as a causal loop diagram. A full explanation how a causal loop diagram works and is used is given in Sverdrup et al. (2018). The eutrophication in the lakes is driven by four reinforcing loops (R), and limited by a number of balancing loops (B). The reinforcing loops keep the system going, the balancing loop slows down the system. Typical is more plankton growth leads to more plankton mass in the lake, which leads to more plankton growth. There is the first loop (R1), a second loop runs over sediments and phosphorus concentration (R2). The more phosphorus, the more plankton growth. And the more growth, the more phosphorus in the sediments, which when they become resuspended (R3), promote more growth. R1 is the reinforcing loop that drives simple first order exponential plankton population growth. The R1 loop itself is pushed from outside by the phosphorus inflow with polluted water. It is limited by the balancing loop B5, when plankton is taken away from the lake by physical outflow with water and B1 when it precipitates to the sediments. R3 is a reinforcing loop running over fish activity, suspending sediments containing dead plankton containing phosphorus and reintroducing that phosphorus to the water column. R2 and R3 are two interlinked reinforcing loops. Water outflow takes phosphorus with it out of the lake, causing a reduction in lake phosphorus concentration (B). It is apparent from the causal loop diagram, that the inflow of phosphorus is actively amplifying the reinforcing loops R1, R2 and R3. From reading the CLD, the obvious remedy is to reduce total phosphorus inflow to the lakes (Sverdrup et al., 1991).

\subsubsection{Phosphorus and Nitrogen Dynamics}

The principle of mass balance is applied to phosphorus, nitrogen, particulate matter and any chemical pollution in general in the lakes. Figures 5, and 6 show the diagrams for phosphorus and nitrogen one lake, and the full diagrams are obtained by combining two such diagrams, one for each Kaban lake. The general mass balance for nitrogen is (Sverdrup et al., 1991, Barkman \& Sverdrup, 1994, Barkman 


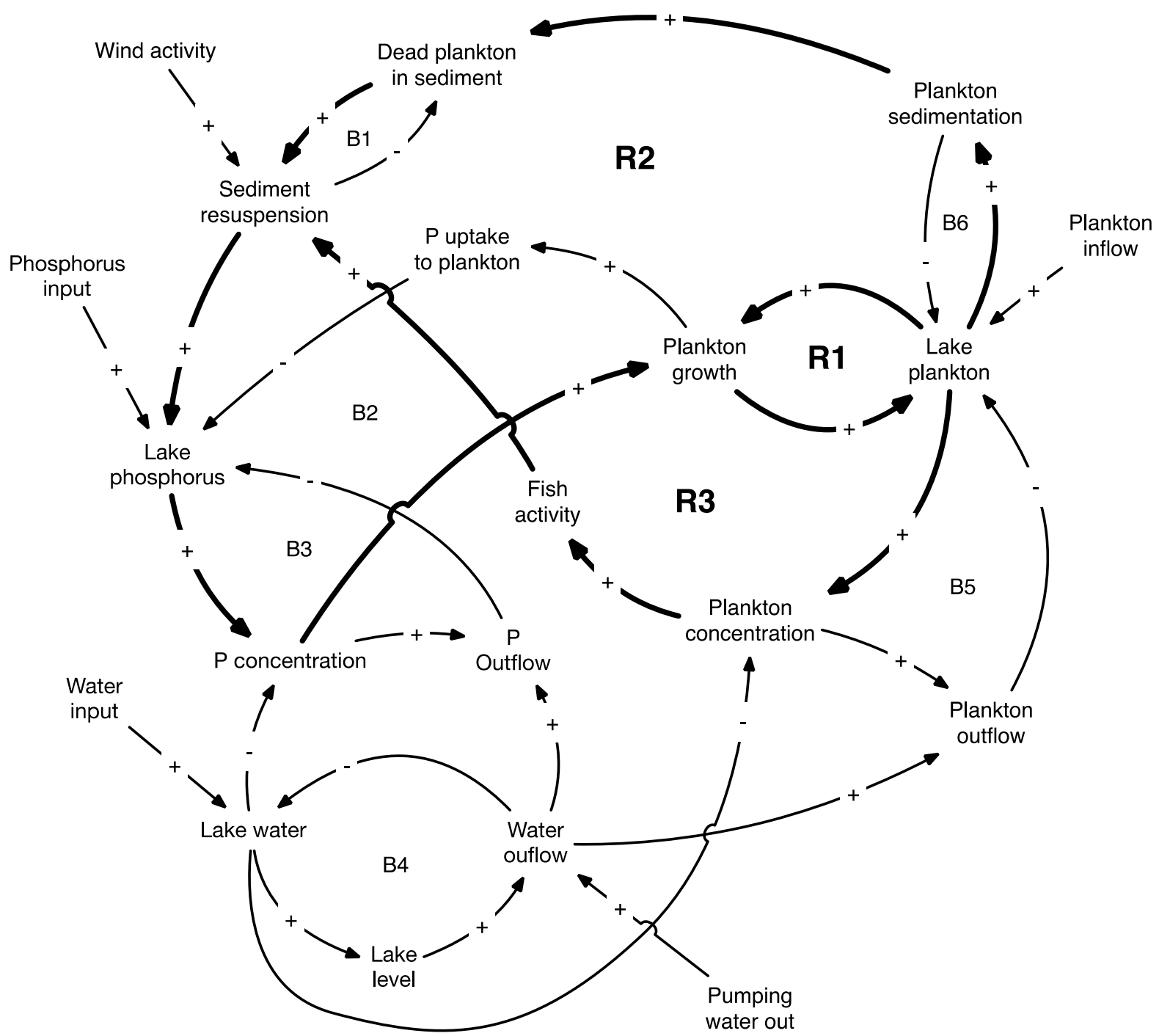

Fig. 4 The causal loop diagram (CLD) for the hydrology, phosphorus and plankton system in the Nizhniy Kaban and Sredniy Kaban Lakes. Please see the text for a detailed explanation of the causal loop diagram

et al., 1994) (See Fig. 5 for the flow chart reflecting the phosphorus mass balance), if the term urban input include both industrial input and city sewage:

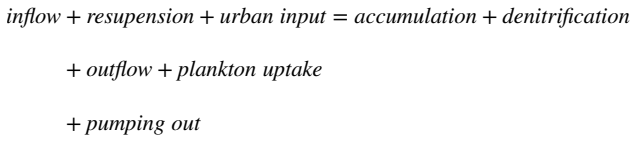

and in the sediment (Sverdrup et al., 1991): sedimentation rate $=$ accumulation + denitrification rate

$$
+ \text { resuspension + removal rate }
$$

The general mass balance for phosphorus (Sverdrup et al., 1991, see Fig. 4 above for the flow chart representing the mass balance for phosphorus in graphical illustration) is:

$$
\begin{gathered}
\text { inflow }+ \text { resuspension }+ \text { urban input }=\text { accumulation }+ \text { outflow } \\
+ \text { plankton upatke }+ \text { pumping out }
\end{gathered}
$$

And in the sediment (Sverdrup et al., 1991):

$$
\begin{aligned}
\text { sedimentation rate } & =\text { accumulation }+ \text { rate of resuspension } \\
& + \text { rate of removal }
\end{aligned}
$$


Fig. 5 Mass balance flow chart for phosphorus in the Nizhniy Kaban and Sredniy Kaban Lakes. The flow chart shows system phosphorus stocks and the phosphorus flows between them

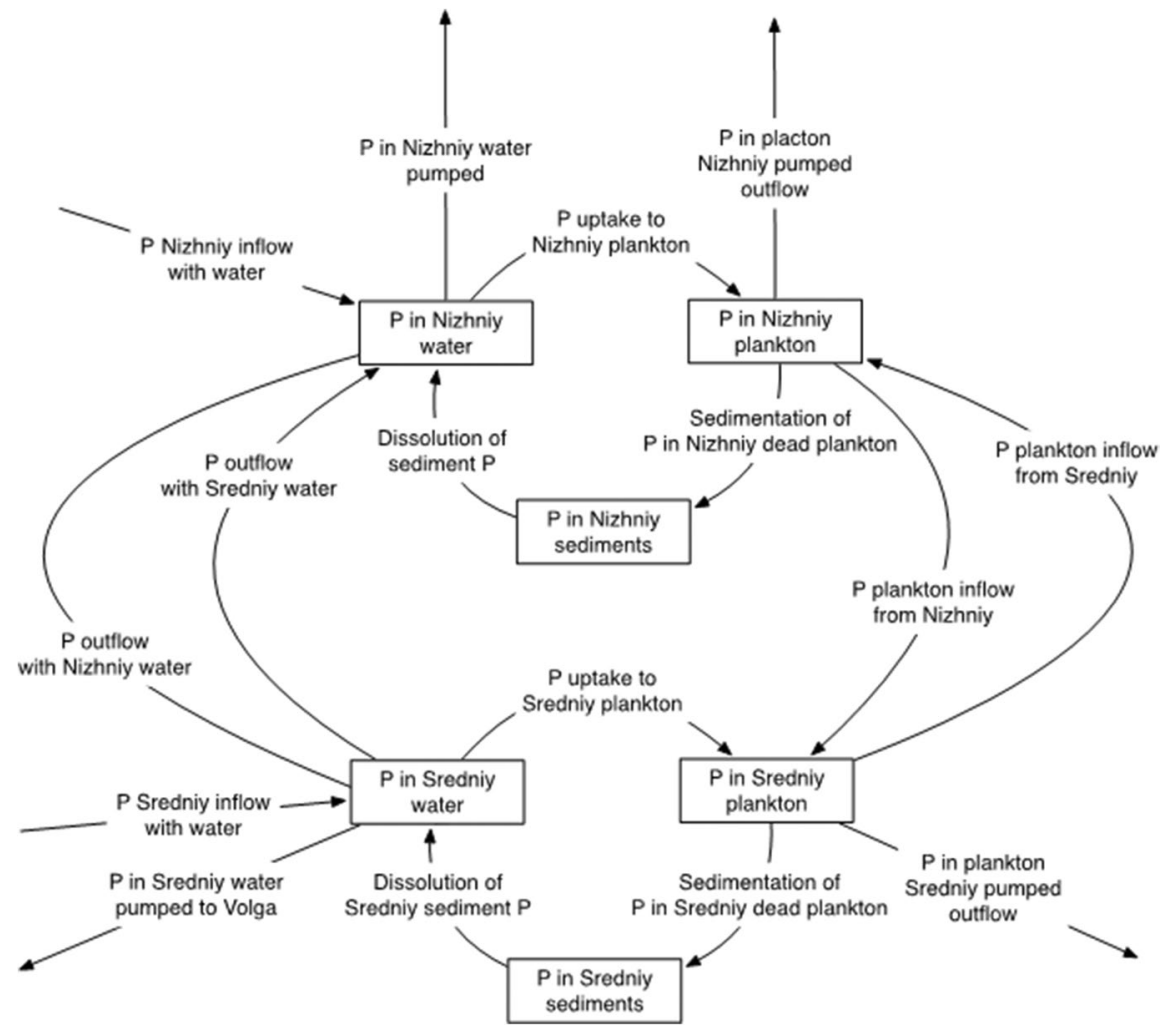

The term "accumulation" is when there is a change in the stock in the water volume. This is seen as a concentration change in the water. Resuspension is resuspension of sediment into the water column by fish activity, boats and wind. The resuspension contributes to particulate concentration, but the resuspended phosphorus and nitrogen dissolves in the water. Nitrogen may become denitrified to nitrogen gas in the sediments (destruction term), and is thus lost from the system. The accumulation is written as the differential.

\subsubsection{Plankton Dynamics}

The general mass balance for plankton is (Sverdrup et al., 1991) according to Fig. 7:

$$
\begin{gathered}
\text { inflows }+ \text { production }=\text { accumulation }+ \text { death }+ \text { outflows } \\
+ \text { pumpingout }
\end{gathered}
$$

The dead plankton settles to the bottom, driving sedimentation of phosphorus and nitrogen (Sverdrup et al., 1991): sedimentation rate $=$ accumulation + resuspension rate

$$
+ \text { removal rate }
$$

Several factors affect the growth of phytoplankton in lakes, and the most important are:

1. Population size and nutrient availability regulate the rate.

2. Light intensity in the lake water column regulates growth intensity.

3. Temperature regulates the activity level.

The growth process is a two-step mechanism, where first the nutrient is taken up by organisms, secondly, that they grow, utilizing the internal nutrients. In many cases, the two processes were lumped into one step. Phytoplankton growth kinetics are described generally with a Michaelis-Menten function, modified with functions taking into account the effects of light and temperature (Sverdrup et al., 1991; Warfvinge et al., 1992): 


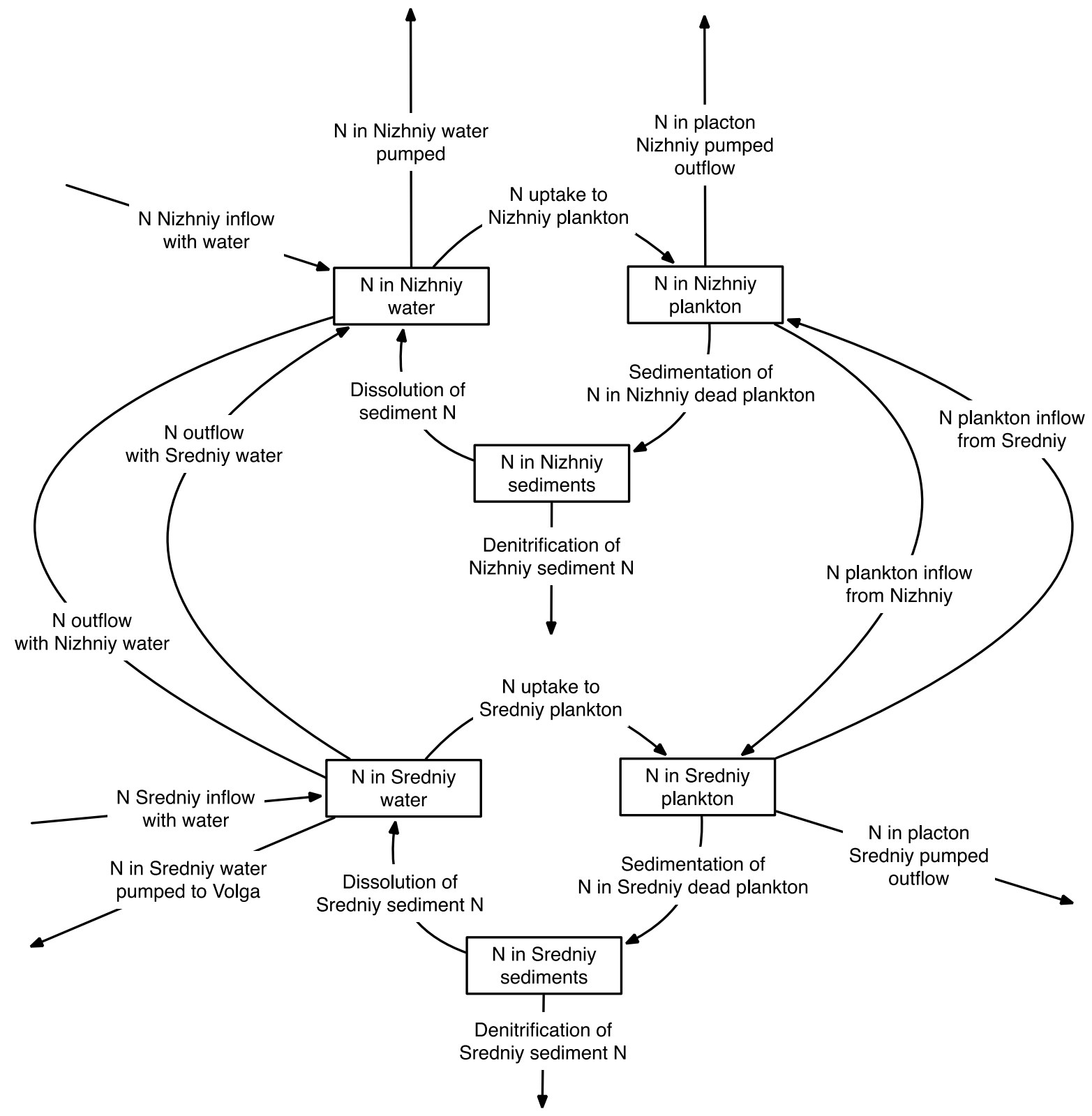

Fig. 6 Mass balance flow chart for nitrogen in the Nizhniy Kaban and Sredniy Kaban Lakes. The flow chart shows system nitrogen stocks and the nitrogen flows between them

$r_{\text {Production }}=k_{\text {Plankton }} * m_{\text {Plankton }} * \frac{[P]}{K_{P}+[P]} * f(I) * g(T)$

$\mathrm{r}_{\text {Production }}$ is a Michaelis-Menten-based equation governed by the assumption that the phytoplankton growth limiting nutrient is phosphorus. [P] is the phosphorus concentration. $\mathrm{m}_{\text {plankton }}$ is the mass of plankton, and $\mathrm{K}_{\mathrm{P}}$ is the Michaelis-Menten saturation coefficient. $\mathrm{F}(\mathrm{I})$ is a function describing light extinction with water depth (Sverdrup et al., 1991) and $\mathrm{g}(\mathrm{T})$ is the temperature dependence of plankton growth (Sverdrup et al., 1991). They have been further described below in the text (Eqs. (8) and (10)). 


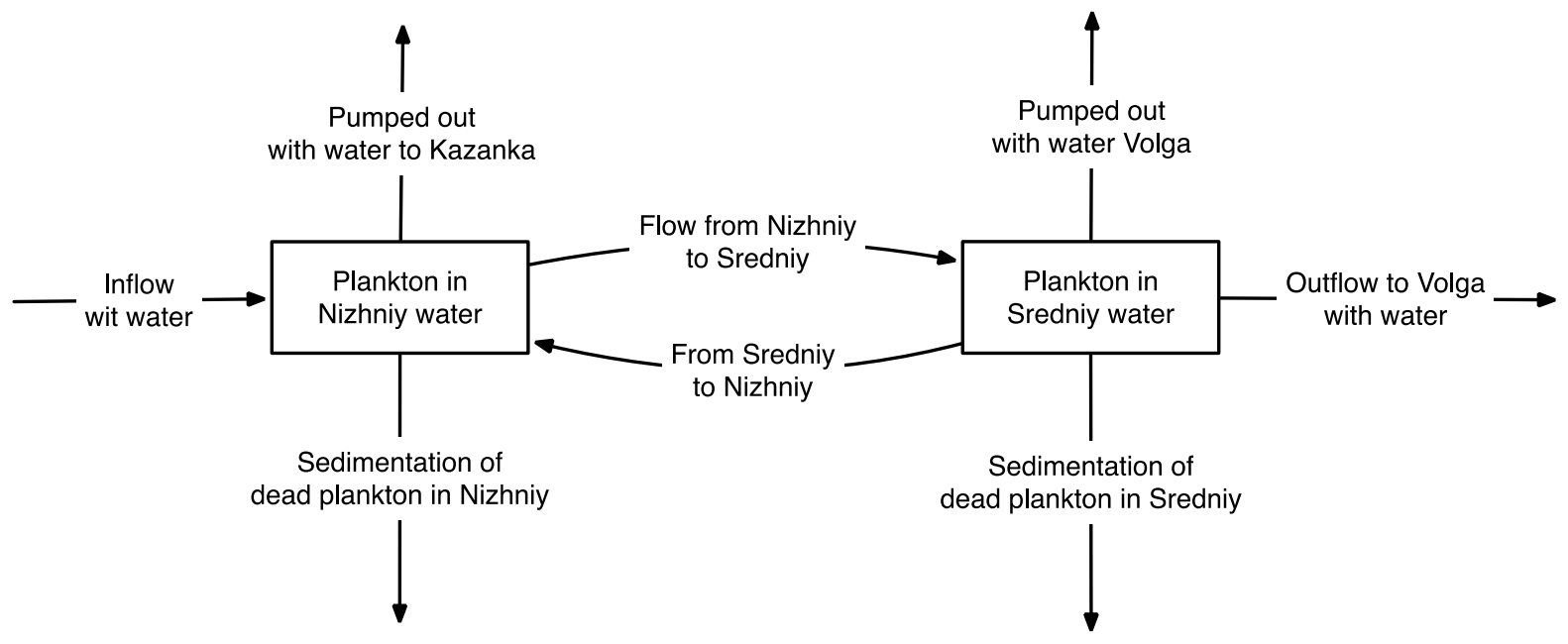

Fig. 7 Mass balance flow chart for plankton in the Kaban lake system. The flow chart shows system plankton stocks and the plankton flows between them

In Eq. (6), the $\mathrm{k}_{\text {plankton }}$ is the growth rate of the phytoplankton population phosphorus reservoir which in this approach has an annual average of $35 \mathrm{yr}^{-1}$. The growth rate depends on the type of plankton and on the metabolic efficiency of the plankton and can therefore deviate substantially from the value in this approach. $[\mathrm{P}]$ is the phosphorus concentration. $\mathrm{K}_{\mathrm{P}}$ is the saturation coefficient which usually varies in the range $0.1-0.01 \mathrm{mg} \mathrm{P}$ per litre. It is assumed that all phosphorus in the water is present in bioavailable form. For the light extinction function $\mathrm{f}(\mathrm{l})$, the form of a negative Hill-function with respect to Secchi depth was used rather than the exact integral of light extinction in the lake water column. The equation used is (Sverdrup et al., 1991, Håkanson et al., 2005):

$f(I)=\frac{1}{1+k_{s} * s^{n}}$

The expression in Eq. (7) approximates the effect of the exact light extinction integral, but is much simpler to use (Sverdrup et al., 1991). The expression will reduce the primary growth rate to $10 \%$ of the normal at a Secchi depth of $0.2 \mathrm{~m}$, and $95 \%$ of normal level at a Secchi depth of $1.5 \mathrm{~m}$. $\mathrm{s}$ is the Secchi depth in the lake, and the parameters have the values $\mathrm{k}_{\mathrm{s}}=0.146$ and $n=-2.55$. The Secchi depth $\mathrm{s}$ is affected by many factors of which particulate matter is one important factor. During the investigations of the lake Ringsjön in Sweden (Sverdrup et al., 1991), the following empirical relationship was deduced from the collected data, but based on the Sverdrup equation (Sverdrup et al., 1942). The equation for $\mathrm{s}$ in Eq. (8) was modified for the Kaban Lakes to become:

$s=1.89-0.87 \log [$ Plankton $]$

where [Plankton] is the concentration of plankton biomass (wet weight, $\mathrm{mg} / \mathrm{l}$ ). The temperature dependence $\mathrm{g}(\mathrm{T})$ can be described by many types of expression. A simple expression is (Sverdrup et al., 1991):

$g(T)=1.08^{T-T_{0}}$

where $T_{0}$ is the temperature where maximum efficiency is achieved. $\mathrm{T}$ is the current water temperature and may be expressed as an annual average or for a specific time of the year. Phytoplankton is being removed from the water column by two principal mechanisms: either natural death or by grazing. Natural death may be expressed as a constant fraction of the population per time. Hence, the expression for loss of plankton phosphorous by natural plankton death may be described according to Eq. (10) (Sverdrup et al., 1991): (Figs. 8 and 9)

$r_{\text {planktondeath }}=k_{\text {plankton }_{\text {death }}} m_{\text {plankton }}$

In the present approach, the predation term is directly coupled to the growth of fish. The mortality of 


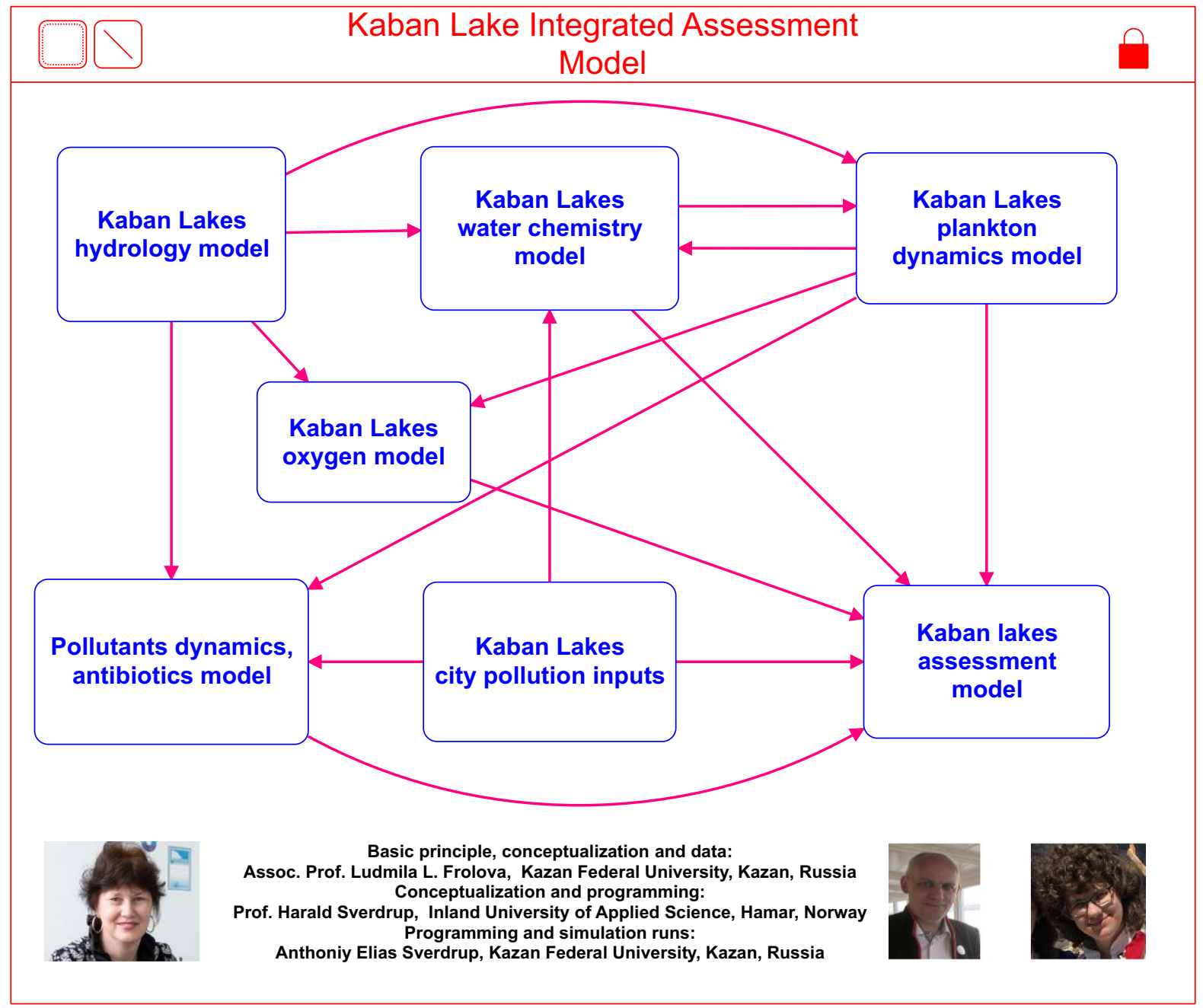

Fig. 8 Overview of the modularized model in the STELLA Architect software, the Kaban Lakes Integrated Assessment Model (KLIAM)

phytoplankton during the summer is considered to be in the range of 35 to $70 \%$ per year. However, the annual average value is in the range $1-2 \%$ per year. The plankton mass balance for the sediments is easier (Sverdrup et al., 1991):

accumulation $=$ sedimentatation rate - resuspension rate

$$
\text { - destruction rate }
$$

Nitrate is denitrified to $\mathrm{N}_{2}$ in the sediments and gasses out. Phosphorus as an element is not degraded, but can be immobilized by chemical precipitation with $\mathrm{Al}$, $\mathrm{Fe}$ and $\mathrm{Mn}$ complexes, and by physical burial in the lake sediments. Phosphorus in biomass is stored as phosphates, and these are released to water when the biomass decomposes (Håkanson et al., 2003, 2005, 2007; Jørgensen et al., 1990).

\subsubsection{Hydrological Dynamics}

Figure 10 shows an overview of the hydrological flows in the system. Physical data for the system is shown in Table 1. The Kaban lakes are characterized by their short water retention times, less than a year in all of them. The Nizhniy Kaban and Sredniy Kaban lakes are connected, and Nizhniy Kaban Lake is connected with the Bulak channel. Very long time ago, the Nizhniy Kaban Lake probably drained out 


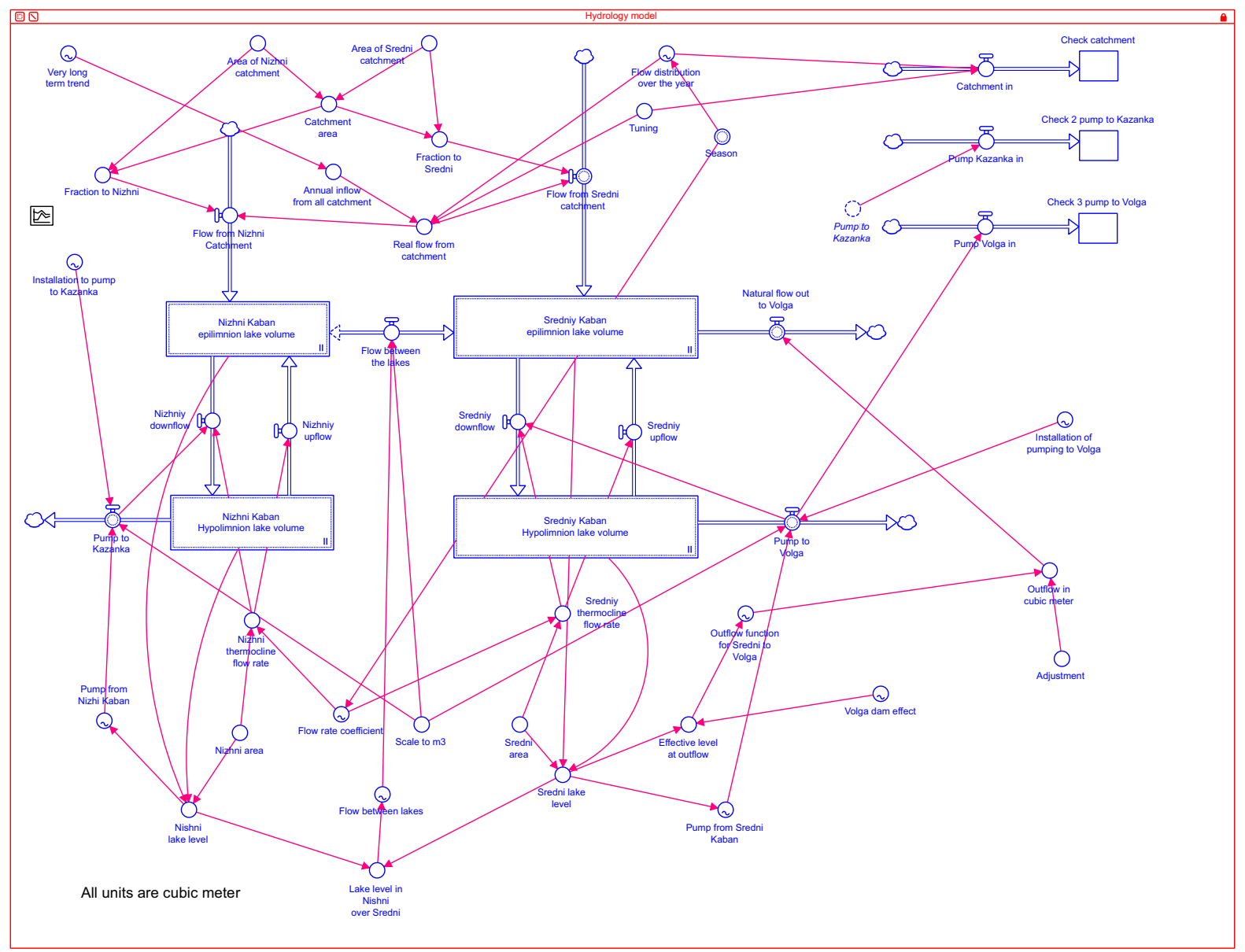

Fig. 9 The hydrological model in the STELLA Architect environment. Both lakes have thermal stratification at about $3-\mathrm{m}$ deep in the summer. The layers completely mix in the fall and spring. White is the city landscape, and green is a more

to the Kazanka River, but the urban development Kazan City in the nineteenth century interrupted that connection. The smaller Verhniy Kaban Lake to the south of the Sredniy Kaban Lake is separate from these lakes and will not be addressed in this study. The basic principle is, the outflow from the lake is driven by height difference. Lake level over the outlet and the lake level difference between the lakes drives flow in the model. In addition, pumping is also driven by lake level, but with different flow characteristics (Fig. 11). rural setting. Large parts of the inflow from the catchment go through underground canalization with pumps before it reaches the lakes. This is a flow chart for water in the system as it appears in the STELLA Architect software

\subsection{The Integrated Model}

\subsubsection{General}

The Kaban Lakes Integrated Assessment Model (KLIAM) has several main parts (Fig. 8):

1. The hydrological module (Sverdrup et al., 2022).

2. The chemistry module where phosphorus, nitrogen, alkalinity and particle matter dynamics is calculated.

3. The biology module where the plankton dynamics is calculated.

4. Pollution dynamics module, handling mineral oils, mercury, cadmium, chromium from tanning, 
Fig. 10 Overview of the hydrological flows in the system. White is the city landscape, and green is a more rural setting. Large parts of the inflow from the catchment go through underground canalization before it reaches the lakes. This is a flow chart for water in the Kaban lake system. From Frolova et al., 2020

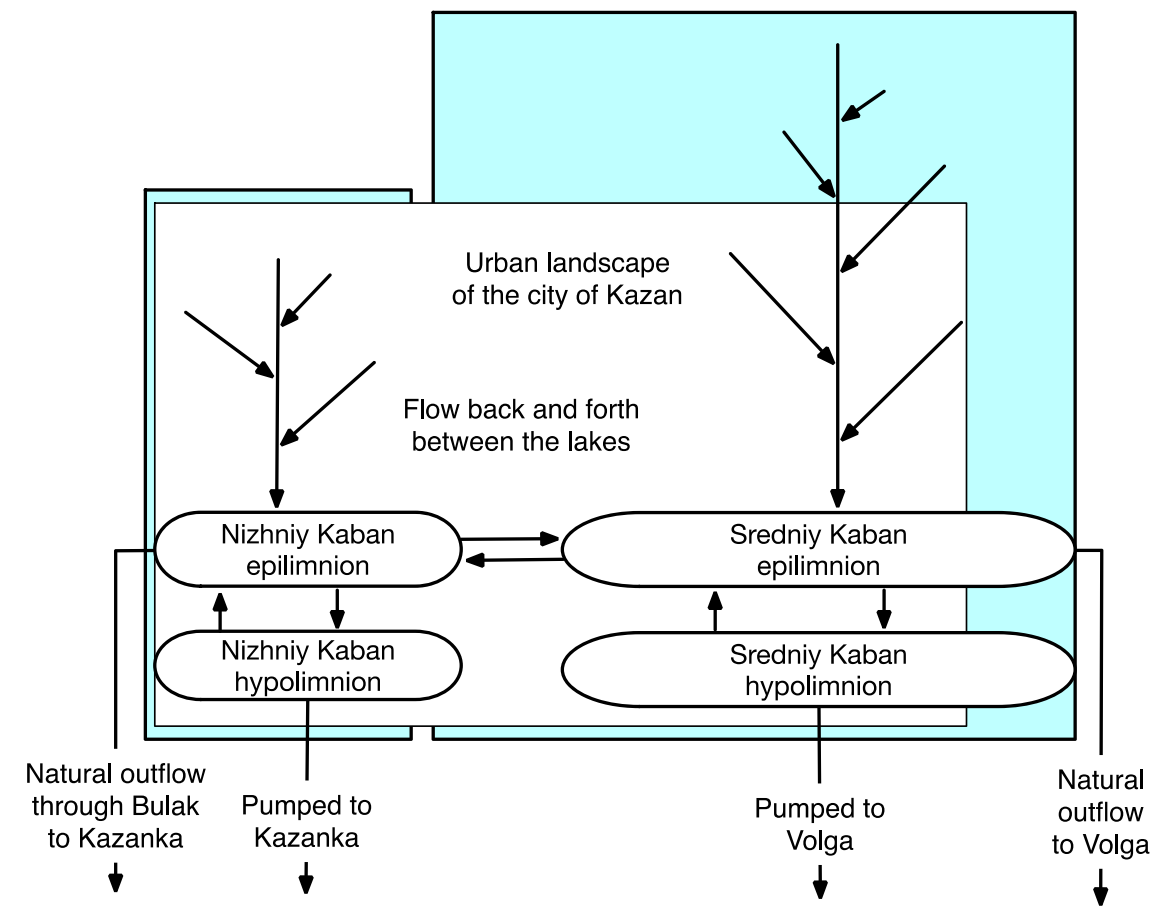

and trace substances in modern times like antibiotics and endocrine disruptors (Frolova et al., 2020; Sverdrup et al., 2020).

5. The Environmental Impacts assessment module.

Inside each box in the diagram, a submodel is situated. The hydrological module inside KLIAM in the STELLA Architect software window is shown in Fig. 8, the boxes are water stocks, the arrows with valves are flows. The thin lines are information transfers.

\subsubsection{Hydrology}

The hydrological flow chart is shown in Fig. 10, and this must be consistent with the programming shown in Fig. 9. The hydrological model was first developed as a single compartment model for each lake, later, in order to develop the oxygen module, a hydrological model involving summer thermal stratification distinguishing an epilimnion compartment and a hypolimnion compartment was developed (Fig. 10). The full hydrological model will be the subject of a separate later publication. The natural water outflow from Sredniy Kaban Lake is driven by height difference. The natural water flow between the lakes is also driven by height difference. In addition comes a number of tubes and pumps used to manipulate the water flow in order to adjust Kaban Lakes water levels. The pumping is done to control level variations in the lake. The indicator value is the water level, in which the pumping is attempting to keep as constant as possible. There is a natural outflow from Sredniy Kaban Lake to Volga. The normal height over the sea is $52 \mathrm{~m}$ for Sredniy Kaban Lake, and the Volga River is on the average $49 \mathrm{~m}$ above sea level. That may however vary with about $2 \mathrm{~m}$ up or down on the Volga side, depending on the seasons. Water is also pumped from Nizhniy Kaban Lake to the Kazanka River. There is no natural outlet from Nizhniy Kaban Lake to the Kazanka River. The capacity of both pumps has been reported to be 25 million $\mathrm{m}^{3}$ per year. The peak pump performance is unknown, but probably in the range of $0.77-1 \mathrm{~m}^{3} / \mathrm{s}$. The water and material flow between the lakes is calculated endogenously in the model. Some of the hydrological dynamics is represented in the lower part of the causal loop diagram shown in Fig. 4. 


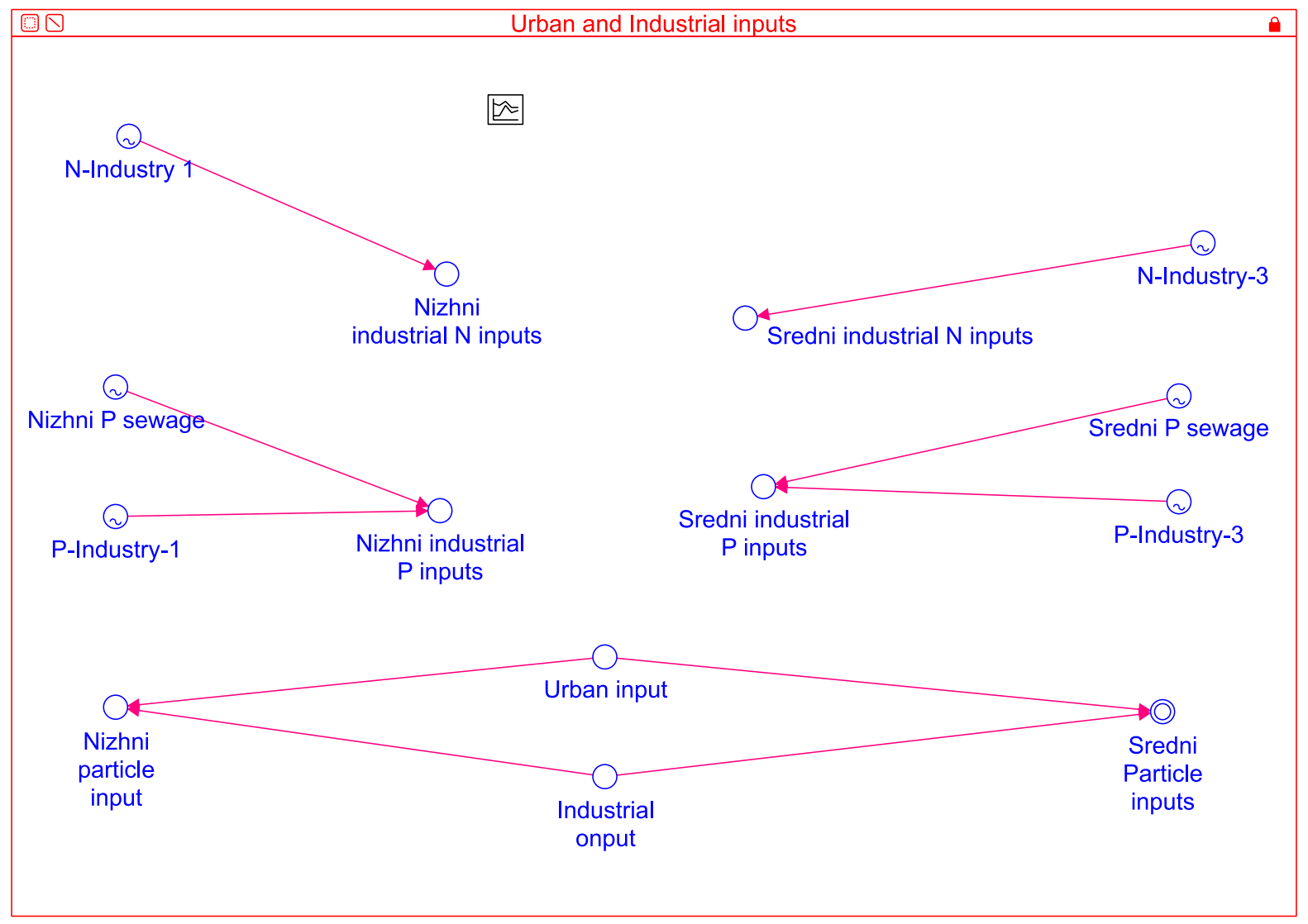

Fig. 11 The industrial pollution input module in the STELLA Architect environment. It handles the different anthropogenic inputs to the catchment area and into the lakes themselves

\subsubsection{Lake Chemistry}

The nitrogen and phosphorus model inside the lake chemistry module is shown in Fig. 12. Figure 11 shows the input module used to set the pollution loads to the Kaban Lakes. The phosphorus model was made from a mass balance over each lake. Each lake module includes mass inflow from the catchment (phosphorus, nitrogen, plankton), flow between the lakes, outflow to Volga River, and pumping to Kazanka River from Nizhniy Kaban Lake and pumping to Volga from Sredniy Kaban Lake, taking water, phosphorus, nitrogen and plankton with it.

\subsubsection{The Lake Plankton Model}

The plankton dynamics model for Nizhniy Lake inside the biology module in Fig. 13, the plankton dynamics model for Sredniy Kaban Lake inside the biology module in Fig. 13. The plankton model follows the structure of the hydrological model, the CLD shown in Fig. 4 and the flow chart for plankton as shown in Fig. 7.

\subsubsection{Parameterization}

The model was parameterized using data collected by the Kazan City authorities and by the Kazan Federal University staff. There is a lack of data for these systems, and to the degree where they have actually been measured, scientific publication of the data seems to be not available. Tables 1, 2, and 3 have been assembled from literature and reports that are only available in the Russian language. Not all numbers can be found and what our guesses are have been given in italics. For several parameters, assumptions were applied because of missing information. Nitrogen and phosphorus flux data have largely not been 


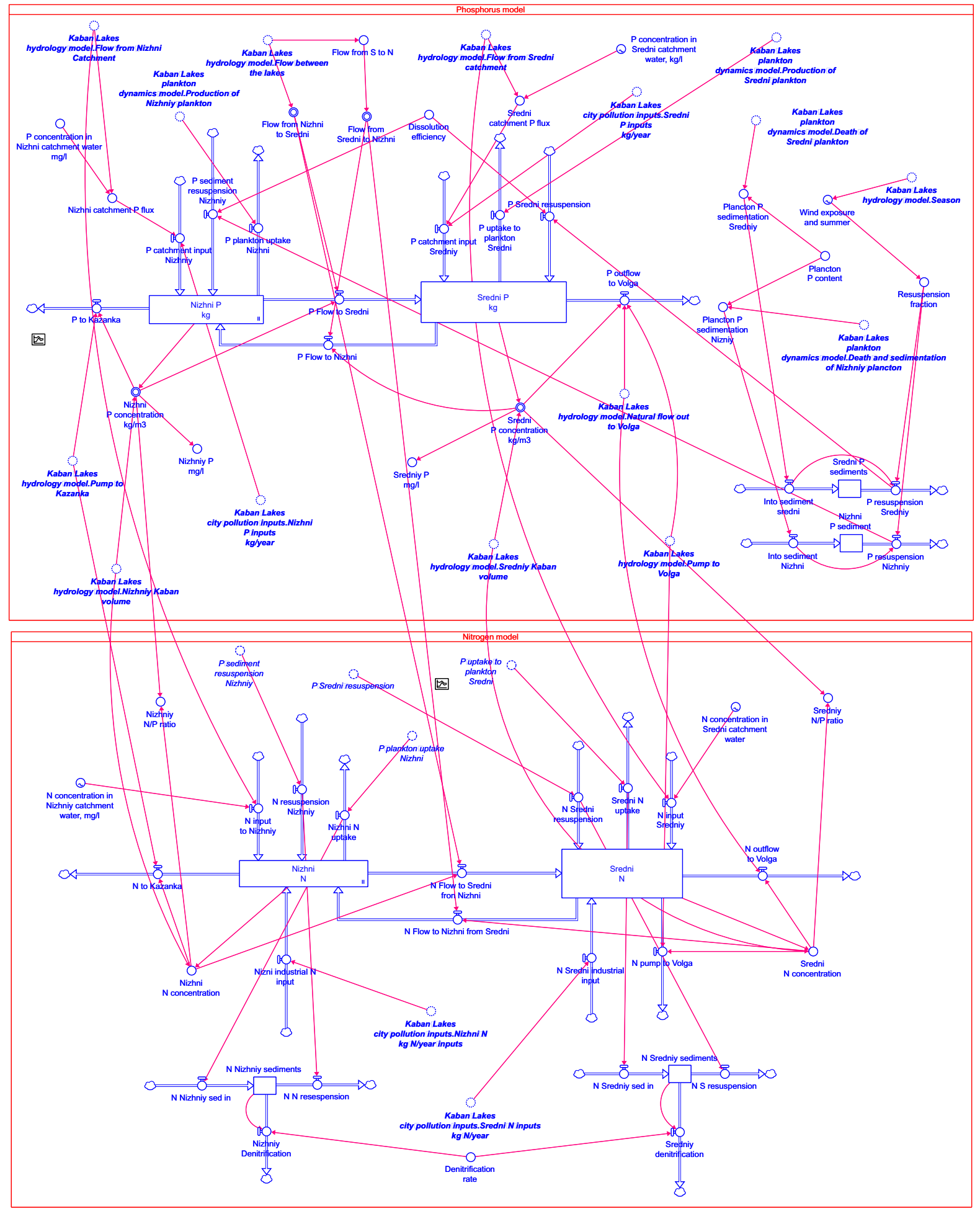

Fig. 12 The nitrogen and phosphorus module in KLIAM in the STELLA Architect environment 


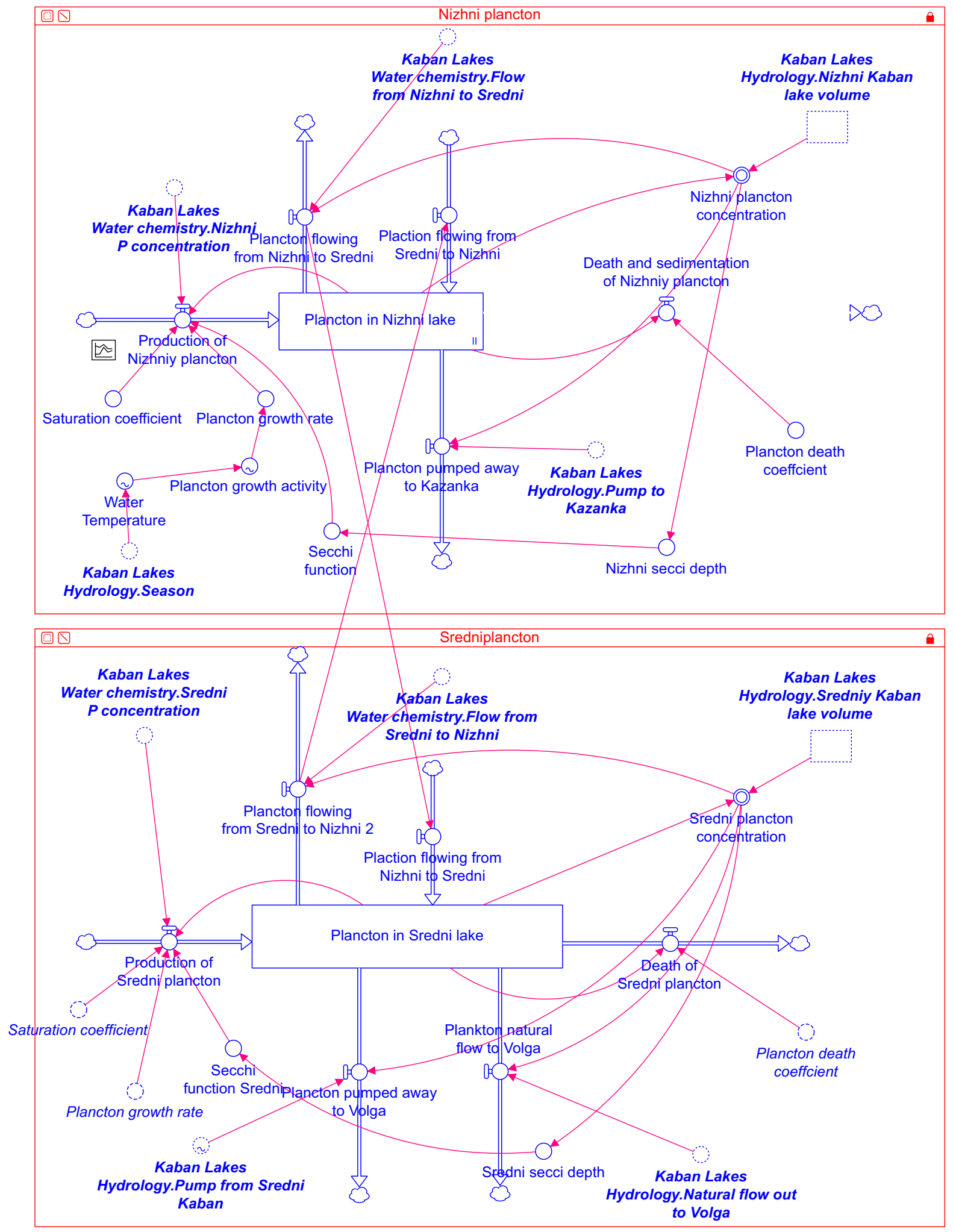

Fig. 13 The plankton modules in KLIAM for Nizhniy Kaban and Sredniy Kaban Lakes in the STELLA Architect environment 
Table 2 Typical lake water composition in Sredniy Kaban Lake found in the literature and Russian local reports on the lake system

\begin{tabular}{|c|c|c|c|c|c|}
\hline Parameter & Units & 1840-1900 & 1995-2000 & 1999-2000 & 2010-2019 \\
\hline Lake $\mathrm{pH}$ & - & & 7.8 & $6.5-8.8$ & $7.1-7.8$ \\
\hline ANC & $\mathrm{Eq} / \mathrm{l}$ & & 100 & & \\
\hline $\mathrm{HCO}_{3}$ & $\mathrm{mg} / \mathrm{l}$ & & & 233 & \\
\hline$[\mathrm{Ca}+\mathrm{Mg}]$ & $\mathrm{mg} / \mathrm{l}$ & & 120 & 131 & Reported as "hard water" \\
\hline$[\mathrm{Na}+\mathrm{K}]$ & $\mathrm{mg} / \mathrm{l}$ & & 200 & & \\
\hline$\left[\mathrm{NH}_{4}\right]$ & $\mathrm{mg} / \mathrm{l}$ & & & 0.53 & $0.4-1.4$ \\
\hline$[\mathrm{N}],\left[\mathrm{NO}_{3}\right]$ & $\mathrm{mg} / \mathrm{l}$ & & 3.25 & 5.5 & Winter 2.9-6.6, Spring 0.4-0.6, Fall 0.56 \\
\hline$[\mathrm{P}],\left[\mathrm{PO}_{4}\right]$ & $\mathrm{mg} / \mathrm{l}$ & & 0.69 & 0.34 & $\begin{array}{l}\text { Spring } 0.19, \text { Summer } 0.52 \text {, } \\
\text { Fall } 0.77, \text { Winter } 0.69\end{array}$ \\
\hline$\left[\mathrm{SO}_{4}\right]$ & $\mathrm{mg} / \mathrm{l}$ & & 200 & & \\
\hline$[\mathrm{Cl}]$ & $\mathrm{mg} / \mathrm{l}$ & & 40 & & \\
\hline [DOC $]$ & $\mathrm{mg} / \mathrm{l}$ & & $3-15$ & & \\
\hline Particulates & $\mathrm{mg} / \mathrm{l}$ & & 121.8 & 15 & \\
\hline Soap & $\mathrm{mg} / \mathrm{l}$ & & & 0.048 & \\
\hline Phenol & $\mathrm{mg} / \mathrm{l}$ & & & 0.0028 & \\
\hline Plankton & $\mathrm{mg} / \mathrm{l}$ & & 2.8 & & $6.2-9.2$ \\
\hline Mineral oil & $\mathrm{mg} / \mathrm{l}$ & & 0.28 & 0.058 & \\
\hline Secchi depth & $\mathrm{m}$ & & 0.52 & $0.3-0.5$ & \\
\hline $\mathrm{O}_{2}$ saturation & $\mathrm{mg} / \mathrm{l}$ & & 18 & & Low to zero in the bottom layers \\
\hline
\end{tabular}

Table 3 Typical lake water composition in Nizhniy Kaban Lake found in the literature, Russian local reports on the lake system and from interviews

\begin{tabular}{llll}
\hline Parameter & Units & $1840-1900$ & $2010-2019$ \\
\hline Lake $\mathrm{pH}$ & - & - & $7.1-7.8$ \\
{$[\mathrm{Ca}+\mathrm{Mg}]$} & $\mathrm{mg} / \mathrm{l}$ & Hard water & Reported as "hard water" \\
{$[\mathrm{N}],\left[\mathrm{NO}_{3}\right]$} & $\mathrm{mg} / 1$ & - & $?$ \\
{$[\mathrm{P}],\left[\mathrm{PO}_{4}\right]$} & $\mathrm{mg} / 1$ & - & $?$ \\
{$[\mathrm{DOC}]$} & $\mathrm{mg} / \mathrm{l}$ & - & $?$ \\
Particulates & $\mathrm{mg} / 1$ & Not clear $(1860)$ & Yes, a lot \\
Plankton & $\mathrm{mg} / 1$ & - & 24.5 \\
Mineral oil & $\mathrm{mg} / 1$ & Visible pollution 1860 & None \\
Secchi depth & $\mathrm{m}$ & Poor transparency & 0.6 \\
$\mathrm{O}_{2}$ saturation & $\mathrm{mg} / 1$ & Rotting water (1860) & Low to zero in the bottom layers \\
\hline
\end{tabular}

found in the published material consulted, neither in English not in Russian language (Glinsky, 1874; Dunaev, 1833). The model was used iteratively to match the observed data when available, in order to estimate what the input phosphorus and nitrogen loads would have been in the past.

We used qualitative historical information for timing of events (See the narratives of Kalimullin, 2005; Kalimullin \& Vinogradov, 2015; Derevenskaya et al., 2015). We used data from other studies in abroad with which the authors were familiar with like the Swedish lakes Ringsjön and Finjasjön for making assumptions and approximations when information or the Kaban Lakes where missing. One of the authors (Sverdrup) have worked with modelling these Swedish lakes in the past (Barkman \& Sverdrup, 1994, Barkman et al., 1994, Sverdrup et al., 1991, Persson et al., 1999). Thus, some of the table you would expect to find in the parameterization section is now in the results section.

Sredniy Kaban Lake had $6.2 \mathrm{mg} / \mathrm{l}$ plankton when it was sampled, the bottom sediments were $2-4-\mathrm{m}$ thick; 
this is after removal of $2-3 \mathrm{~m}$ of sediments took place in around 1990-2000. Sredniy Kaban Lake had more industries in the past, starting from 1850 and expanding until 1950. The Nizhniy Kaban Lake is more eutrophic and receives more city input of domestic sewage and water from street drains than industrial waste flows. In 1928, substantially larger and more modern industry comes to Kazan and this gets located around the Kaban Lakes, mostly along the shores of the Sredniy Kaban Lake. This is meat industry, tanneries and textile industry, as well as a sulphuric acid, hydrochloric acid and nitric acid factory (Derevenskaya et al., 2015; Kalimullin, 2005; Kalimullin \& Vinogradov, 2015). A thermal powerplant is located on the shore of the Sredniy Kaban Lake, that means it is a coal-fired power plant there (The chimneys can be seen in one of the photographs, it is still there). It takes its cooling water for the lake and puts the heated water back into the lake $\left(3.3 \mathrm{~m}^{3}\right.$ per second). This keeps the lake $2-3^{\circ}$ warmer than the Nizhniy Kaban Lake (Derevenskaya et al., 2015). Before pollution mitigation, the waste from the smoke stack scrubbers were also dumped in the lake, hence the copper, zinc and mercury pollution, as well as excess nitrite.

For the year 2011, the following measurements were found: Nizhniy Kaban Lake plankton concentration was $24.5 \mathrm{mg} / \mathrm{l}$, at the bottom of the lake there is 6-15-m thick layers of sediments. In the channel between the lakes, plankton concentration $9.5 \mathrm{mg} / \mathrm{l}$ has been observed.

Derevenskaya et al. (2015) describe the mitigation programme conducted in 1980-1990 on the Kaban lake system. They describe the measures used to reduce phosphorus inputs to the Kaban Lakes and give examples of Kaban Lakes' chemistry parameters, but data to be used as proper model validation or parameterization is insufficient. We have found no published estimates of pollution loads (ton per year for phosphorus, nitrogen, copper, zinc, mercury, mineral oil, organic waste nor sewage amounts) for the lakes. The numbers used where scaled from other cities (Barkman et al., 1994; Sverdrup et al., 1991) on a per capita basis (Håkanson \& Peters, 1995; Jørgensen et al., 1990; Håkanson et al., 2003, 2005, 2007, Mameus and Håkanson, 2004). Stormwater drains from the city streets have been dumped into the Nizhniy and Sredniy Kaban lakes until the mid-1990s (Derevenskaya et al., 2015).

The reconstructed phosphorus pollution load curves for Nizhniy and Sredniy Kaban Lakes are shown in Fig. 14. These were constructed from narratives and scaled using load curves from Swedish lakes, scaled on a per capita basis to the population in the catchment. Urban sewage from the Kazan city contained both nitrogen and phosphorus in large amount, in a P:N ratio of about 1:10. In the agricultural and industrial sewage, the $\mathrm{P}$ content may be higher and the ratio P:N is not constant. The simulations are very uncertain, because the nitrogen input load values to the lakes are very uncertain assumption. Figure 15 shows the industrial pollution inputs of nitrogen to the lakes plotted as a function of time as was reconstructed by the authors, using iterative simulations for the two lakes.

A distribution of the water precipitation during a year for the Kazan area was used to distribute annual runoff from the catchment (ClimateData.org, 2020). The precipitation arrives as snow from November, and continues in December, January, February and
Fig. 14 Industrial phosphorus inputs to the lakes plotted as a function of time as was reconstructed by the authors, using iterative simulations for the Kaban Lakes. The uncertainties in the estimate are unknown and probably substantial, and not much quantitative data on pollutant inputs can be found

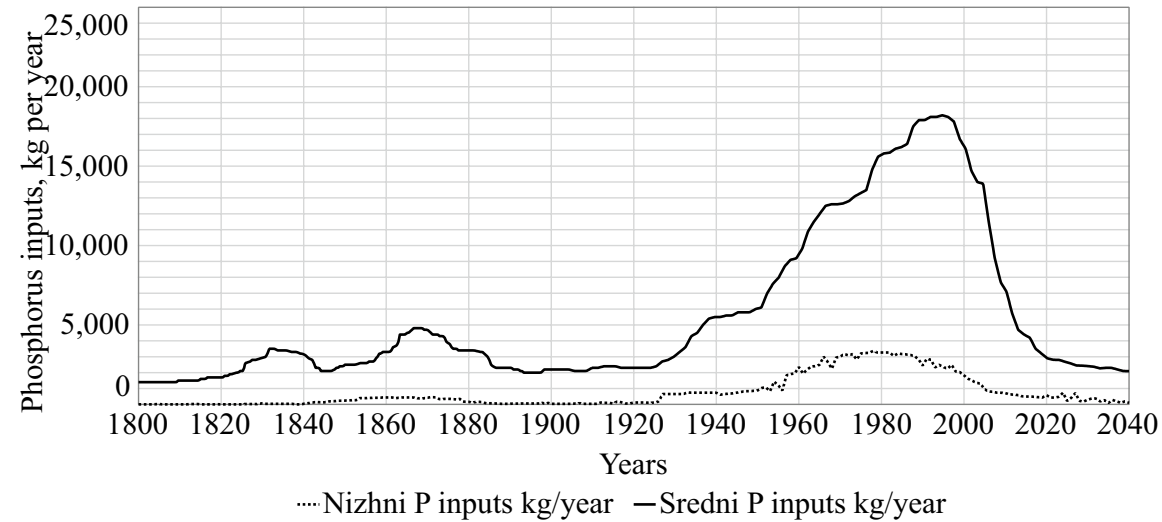


Fig. 15 Nitrogen inputs to the lakes plotted as a function of time as was reconstructed by the authors, using iterative simulations for the two Kaban Lakes. The uncertainties in the estimate is unknown and probably substantial, and not much quantitative data on pollutant inputs can be found

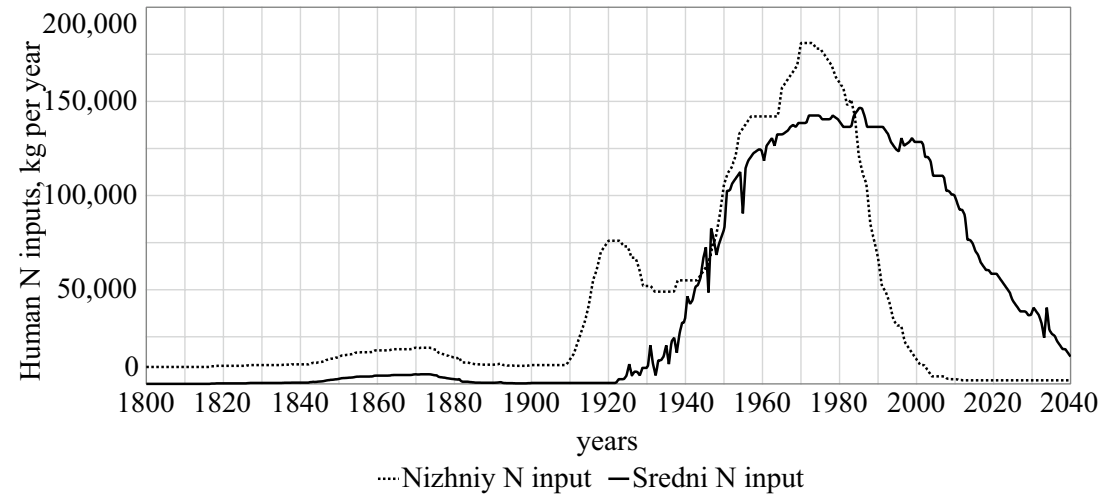

most of March, and arrives in the runoff during the last half of March and first half of April when the snow melts.

\section{Results}

In order to capture the long history of pollution, the whole period from 1800 to 2100 in the future was simulated. The time step was 1/730 year, implying a half-day timestep. The short time-step was necessary for the numerical integration of the simulation model to be convergent and stable. Note that the timestep is a mathematical feature internal to the model, and it is not connected to output reporting interval. Initially, the model was used to check if the results obtained are consistent over both the short term and long term with our experiences from other modelling studies. Not enough field data were available for making a straight model verification at the Kaban Lakes. The timestep used implies that results can be reported down to daily outputs if wanted. The model was first parameterized with the existing data and run as business-as-usual, without any further efforts after 2020.

\subsection{Hydrology}

Figure 16 shows the simulated Nizhniy Kaban and Sredniy Kaban Lakes long-term flow for the period 1900-2100. The flow changed over time in the two Kaban Lakes, and the pumping changed the hydrology substantially after 1935. In 1954-1957, the Kuybyshev Reservoir was built, and this changed the hydrodynamics of the whole region.

The results for the short-term Kaban Lakes hydrology dynamics is shown in Figs. 17-18. These graphs show the water flow over time for water from the

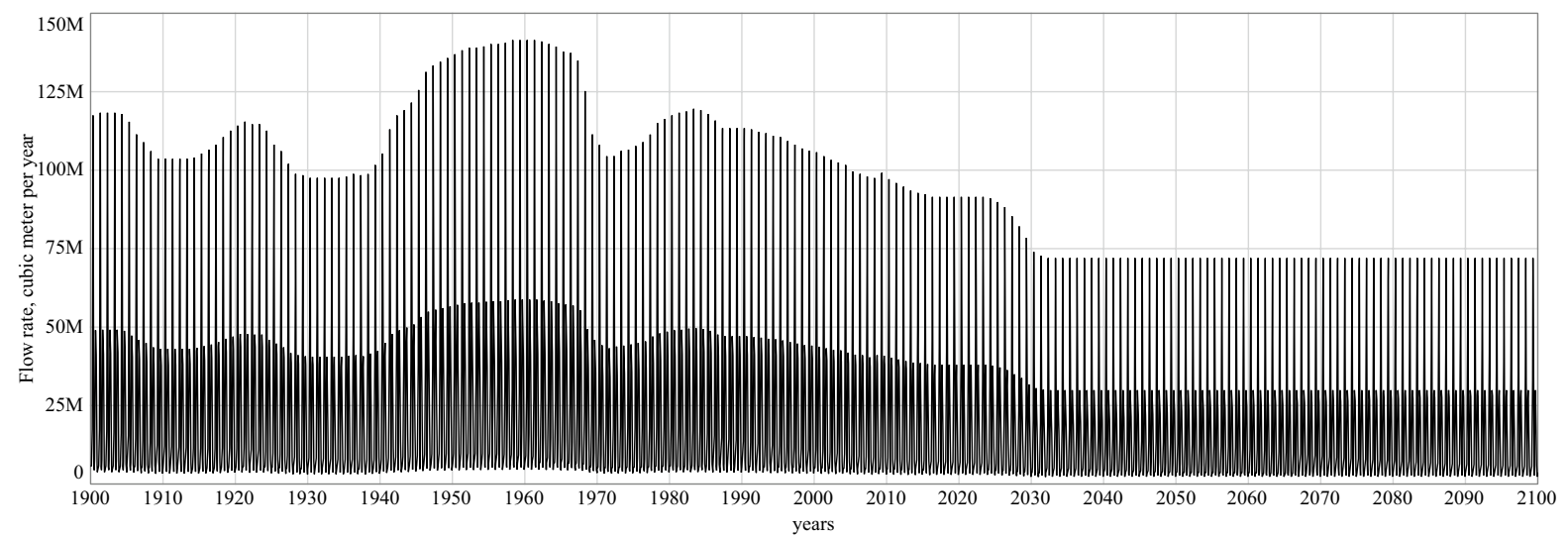

Fig. 16 Simulated Nizhniy and Sredniy Kaban Lakes inflow for 1900-2020. The flow change over time in the two lakes, and the pumping changed the hydrology substantially. We have omitted the period before 1900, as we have less emphasis on the distant past 
catchments for each lake. Figure $17 \mathrm{a}$ and $\mathrm{b}$ shows the simulated pumping of water between the Kaban Lakes during 2012-2014. Figure 18a and b shows the simulated out flows between and from the Kaban Lakes during 2000-2004.

The pumping stabilized the level a lot in both Kaban Lakes, but the dynamics in complex because of the pumping from both lakes and the flow between them. The pumping stations were installed 1935 in Nizhniy Kaban Lake and in 1955 in Sredniy Kaban Lake. Historically, Nizhniy Kaban Lake level was higher than Sredniy Kaban Lake, but the pumping has changed that and actually made the difference more dynamic and larger. The lake dynamics is quite sensitive to how the pumping is managed, as well as it influences the flow between the Kaban Lakes very substantially. Nizhniy Kaban Lake is much more affected by human activity in all ways, and thus, it affects Sredniy Kaban Lake substantially because water is sent from Nizhniy Kaban Lake to Sredniy Kaban Lake. The details of the hydrological model is being published in a separate paper (Sverdrup et al., 2022), where much

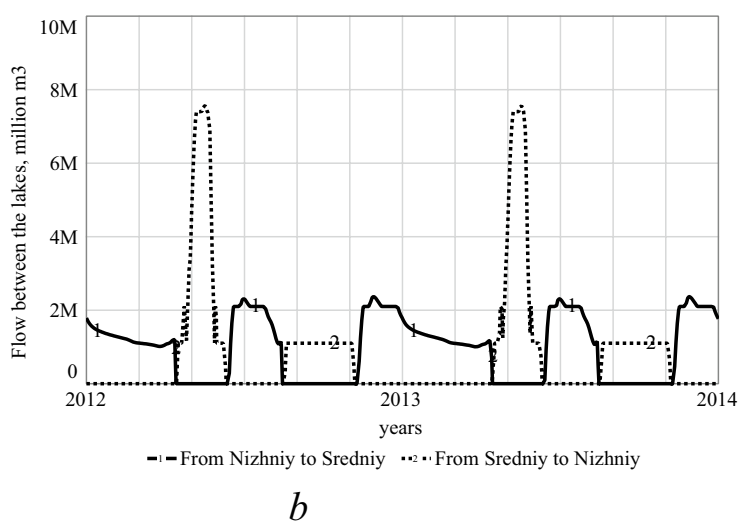

Pumping takes place in spring and fall when the increased flows would have raised the lake levels. Water goes back and forth between the lakes
Fig. 17 Simulation of internal water exchange between the lakes. a Simulated pumping of water from the lakes 20122014. b Simulated flows between and from the two lakes 2000-2004, showing how the flow varies within a single year.

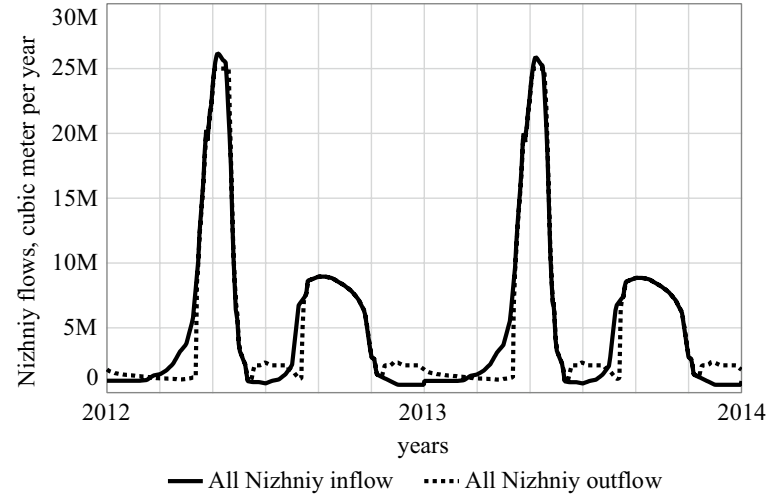

$a$

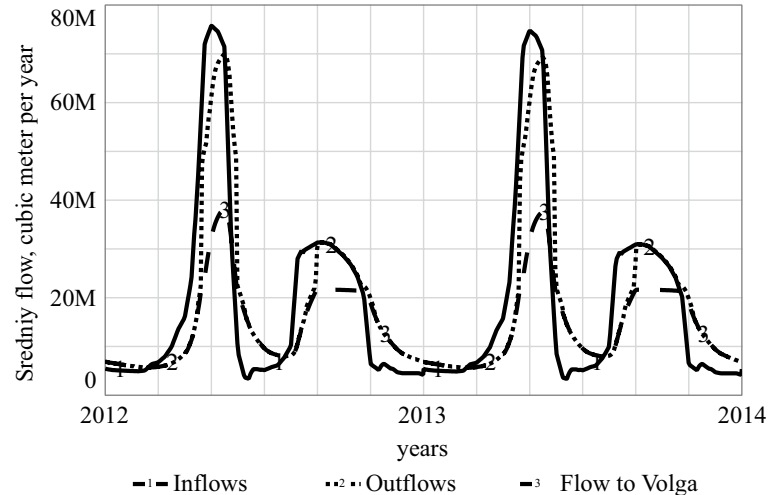

$b$

Fig. 18 Hydrological outputs from the model, showing the flow of water from Nizhniy (a) and Sredniy Kaban Lakes (b) for 2012 to 2014 , illustrating the variation within a year 
more results for hydrodynamics of the Kaban lake system are shown.

\subsection{Phosphorus Dynamics}

Figure 19 shows the phosphorus concentration in the Kaban Lakes 1800-2040. Figure 20 shows the short-term variations in phosphorus concentration the lakes. Between 1930 and 2010, Nizhniy Kaban Lake was in a very polluted state, and they were judged to be unfit as a drinking water source for Kazan city and as a recreational object for bathing and swimming (Vishlenkova, 2005). Sredniy Kaban Lake was not appearing as heavily affected by pollution until later, but it was still in a severe eutrophic state in absolute terms (Derevenskaya et al., 2015). Unfortunately, there is little data available for a full model testing (Figs. 21 and 22).

Figure 23 shows the $\mathrm{N}: \mathrm{P}$ ratio in the lakes 1900-2040 as simulated with the model. The higher the $\mathrm{N}: \mathrm{P}$ ratio, the higher the likelihood of blue-green algae and cyanobacteria blooms. Blue-green algae and cyanobacteria blooms will make the lake water unsuitable for bathing and swimming and unfit as a drinking water source.

\subsection{Nitrogen Dynamics}

Figure 21 shows the nitrogen concentration in the lakes 1800-2040 from the KLIAM simulations. It can be seen that the nitrogen and phosphorus levels were elevated above the background already in 1920. By 2020, Sredniy Kaban Lake had mostly been recovered, but Nizhniy Kaban Lake still showed elevated levels. Figure 22 show an expansion of the results for 2004-2008 so that the yearly variations can be seen. The industrial input includes both industrial sewage with waste and urban sewage. The urban sewage was untreated until about 1997 (Derevenskaya et al., 2015; Vishlenkova, 2005). Unfortunately, there is too little data available for exact estimates of the pollution amounts and the subsequent reduction. A full model

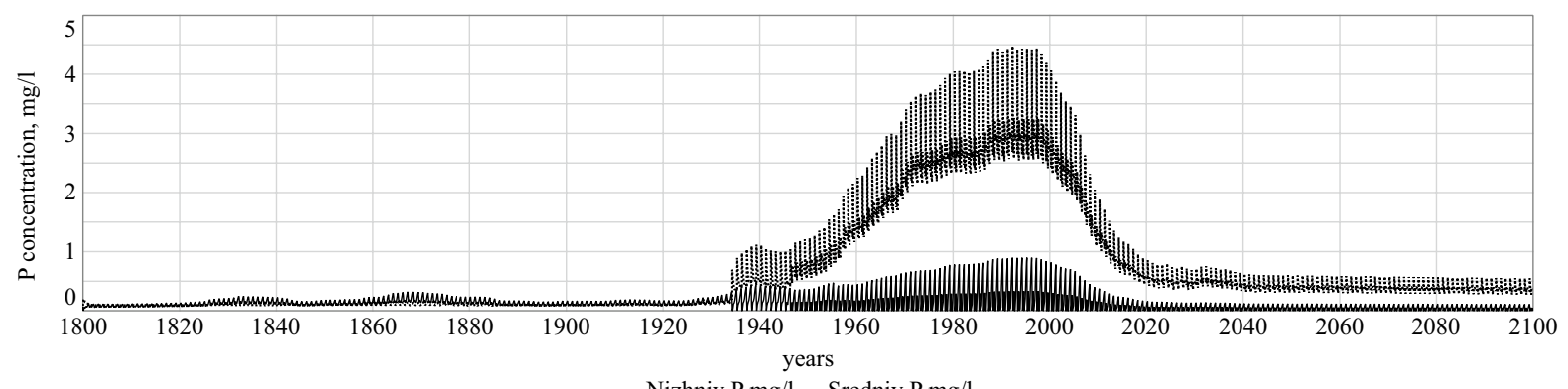

Fig. 19 Phosphorus concentration in the Nizhniy and Sredniy Kaban Lakes 1900-2040. The lake had not fully recovered by 2020

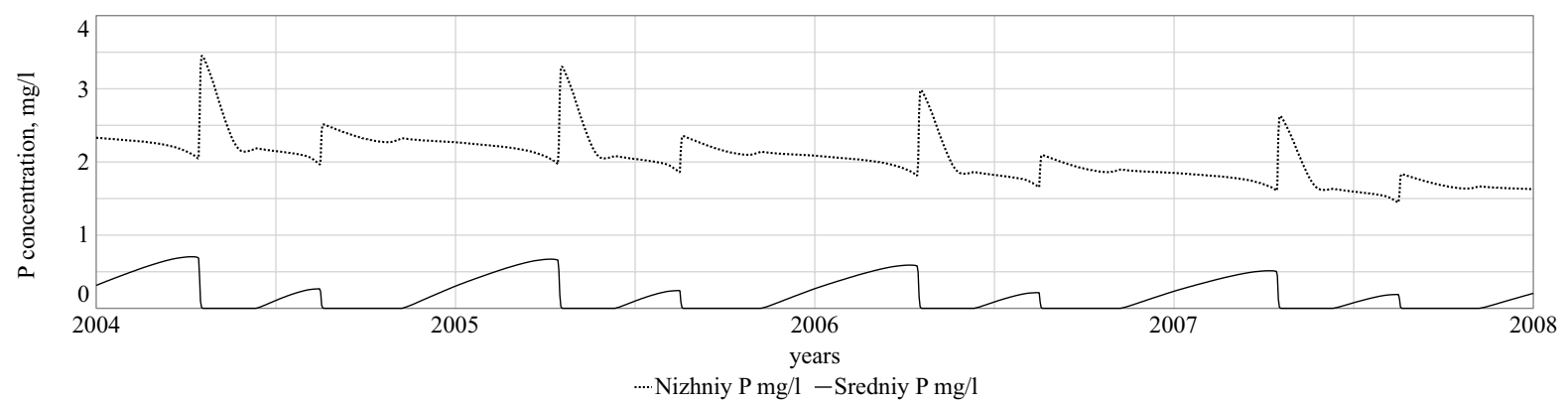

Fig. 20 Short-term variations phosphorus concentration the Nizhniy and Sredniy Kaban Lakes. Adopted from Fig. 18. The phosphorus concentrations seem to fit the observations (Table 2) 


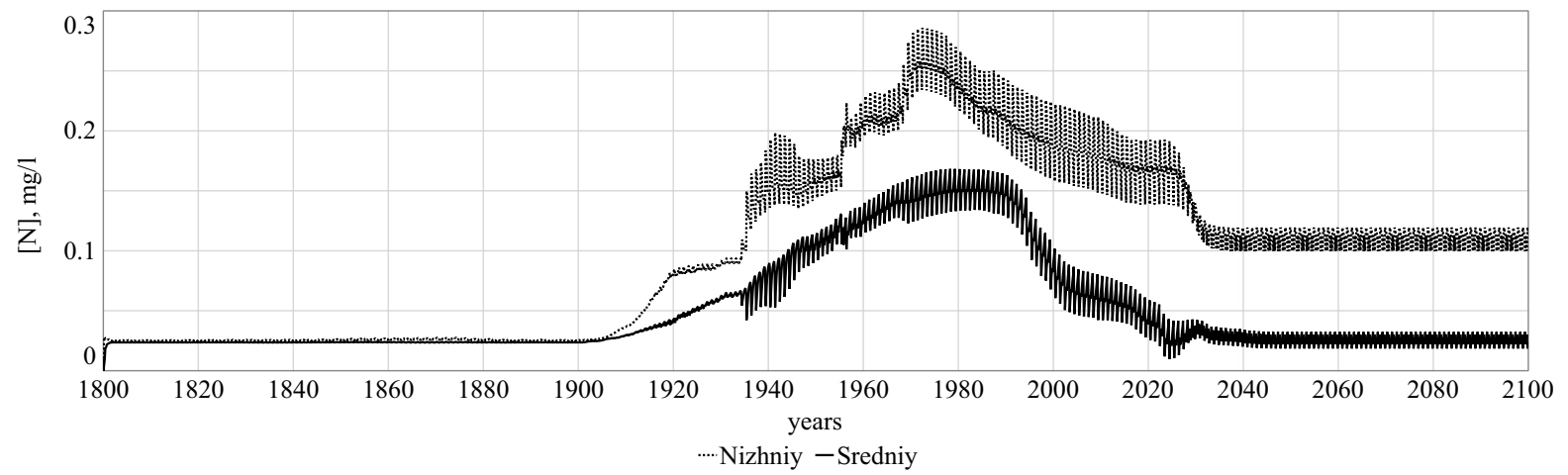

Fig. 21 Nitrogen concentration in the Nizhniy and Sredniy Kaban Lakes 1800-2100 as simulated by KLIAM. The Nizhniy Kaban Lake had not fully recovered by 2020, whereas Sredniy Kaban Lake is suggested to have recovered from nitrogen pollution

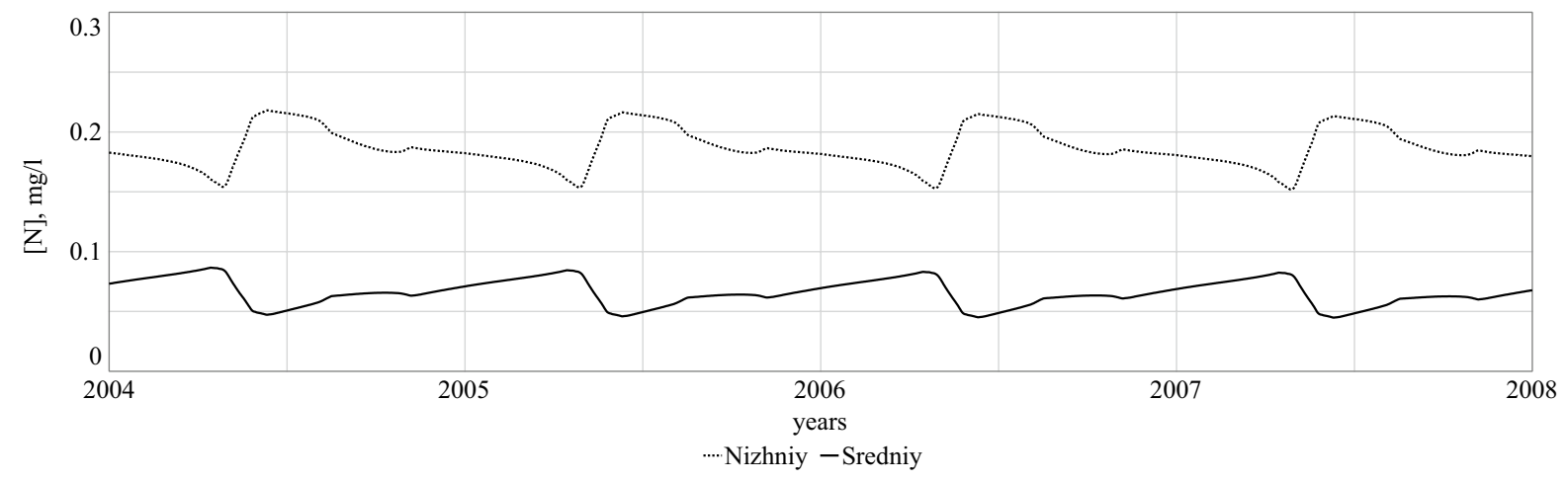

Fig. 22 Short-term variations in nitrogen concentration in the Nizhniy Kaban and Sredniy Kaban Lakes in mg/l of total nitrogen. The annual variations can be seen. Adopted from Fig. 21

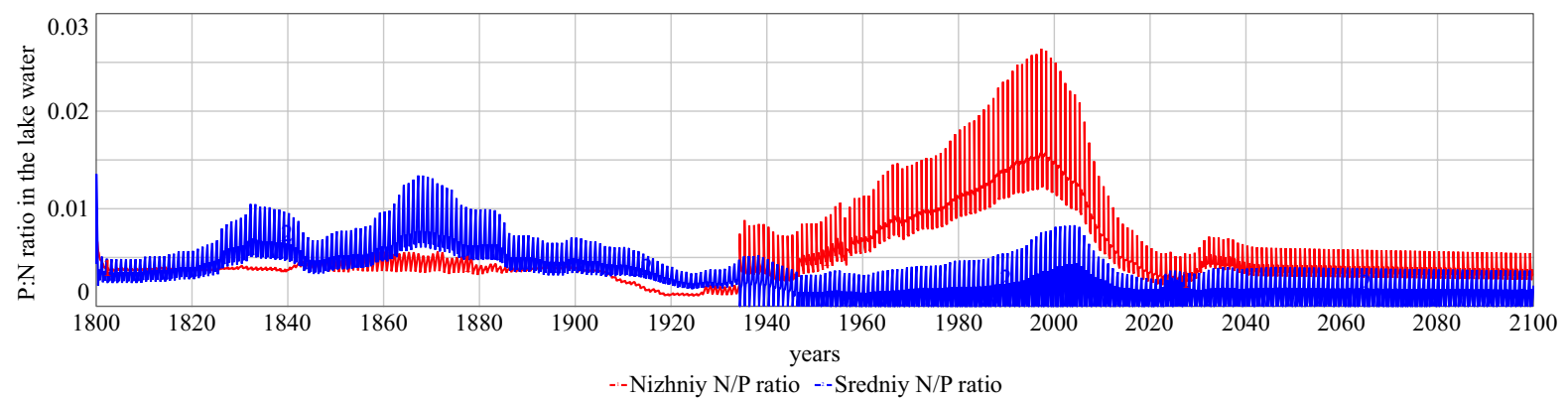

Fig. 23 N:P ratio in the lakes 1800-2040 as simulated with the model. The higher the N:P ratio, the higher the likelihood of bluegreen algae and cyanobacteria blooms

validation was not possible for the nitrogen nodule due to lack of data for the Kaban lake system.

\subsection{Plankton Dynamics in the Kaban Lakes}

The KLIAM was used to model both the short-term 
and the long-term variations seen in the ecological state of the Kaban Lakes as expressed by the plankton concentrations in the water column. Figure 24 shows the plankton concentration in the lakes $1800-2040$ as simulated with the KLIAM. The simulations show how the plankton concentration increased already before 1920 in the Nizhniy Kaban Lake and about 1940 in the Sredniy Kaban Lake.

Figure 25 shows the short-term variations in plakton concentration in the Kaban Lakes according to the simulations.. The Sredniy Kaban Lake improves in the winter, but Secchi deth decreases in the summer as the alge and plankton start growing. During the time period 2000-2010, the plankton concentration in Sredniy Kaban Lake was observed in the range from $3 \mathrm{mg} / \mathrm{l}$ to $15 \mathrm{mg} / \mathrm{l}$ (Table 2). The plankton concentration in Sredniy Kaban Lake is represented by the blue line in the diagram in Fig. 25. Plankton and Secchi depths are closely connected, and both are used in Kaban lake water quality classifications.

\subsection{Secchi Depth Dynamics in the Kaban Lakes}

Low Secchi depth is one of the parameters for evaluating if the Kaban Lakes will be healthy enough for public bathing and recreation. Figure 26 shows the Secchi depth in the Kaban Lakes 1800-2100 as simulated with the model. Figure 27 shows the short-term variations in Secchi depth in the Kaban Lakes according to the simulations. The simulations

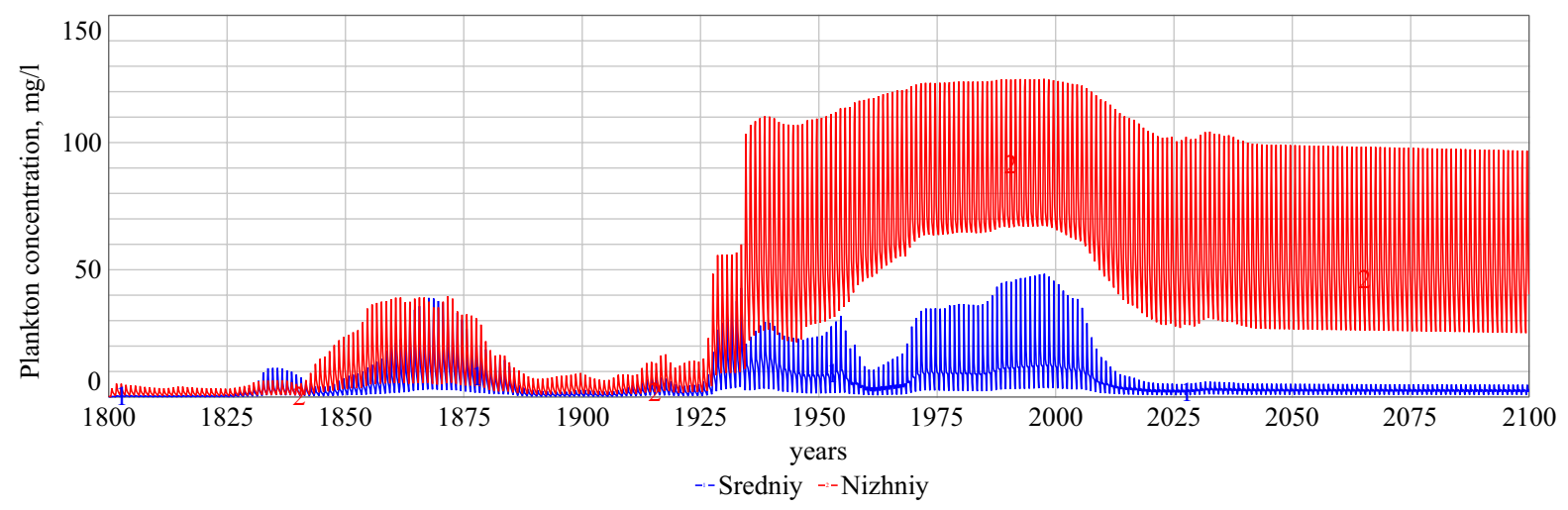

Fig. 24 Plankton concentration in the Nizhniy and Sredniy Kaban Lakes 1800-2040 as simulated with the model. It can be seen how the lakes were eutrophied during 1850-1880 and later from 1030 to the present. The state of Sredniy Kaban Lake has recovered much after 2020, more than the Nizhniy Kaban Lake, which is still strongly polluted

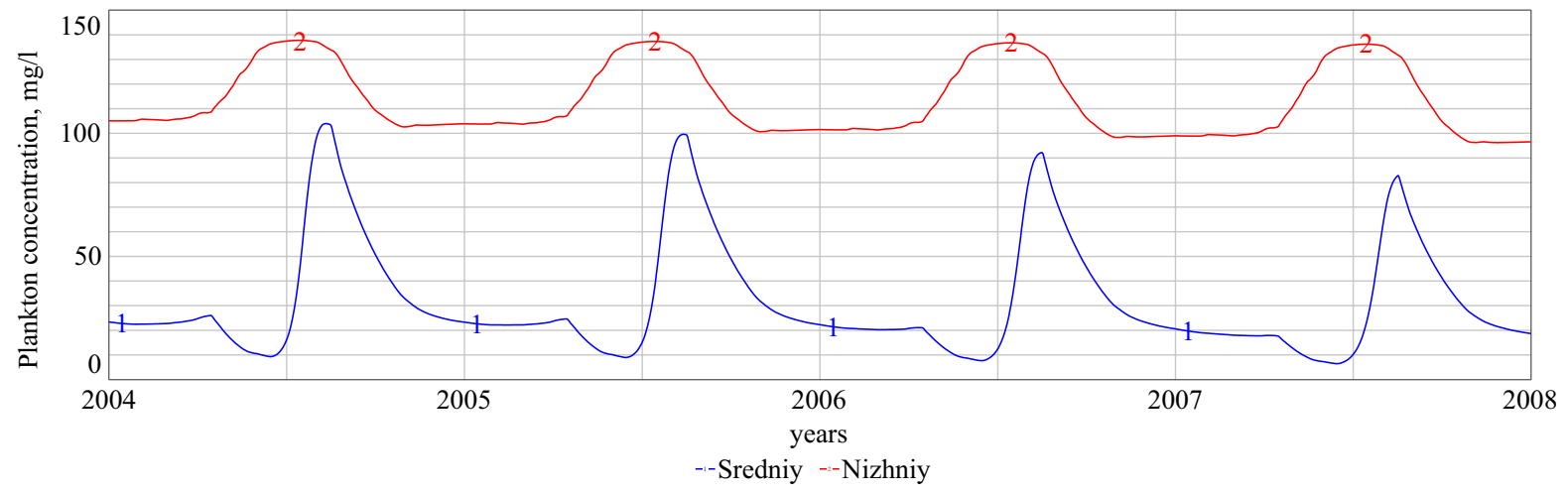

Fig. 25 Short-term variations in plakton concentration in the Nizhniy and Sredniy Kaban Lakes according to the simulations for the years 2004 to 2008 . It can be seen that the lakes clear up in the winter and become turbid during the warm season. Adopted from Fig. 24 


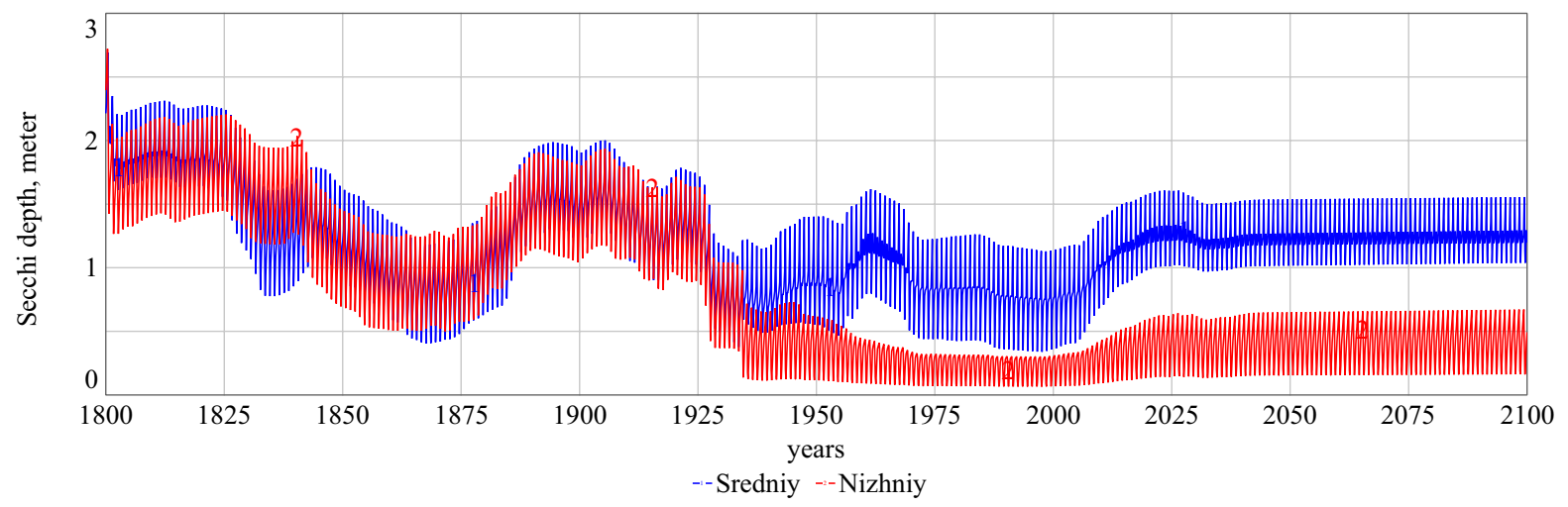

Fig. 26 Secchi depth in the Nizhniy and Sredniy Kaban Lakes 1800-2040 as simulated with the model. The simulations suggest that Sredniy Kaban Lake may further improve in water quality

show how the Kaban Lakes became turbid and muddled already before 1920 in Nizhniy Kaban Lake and about 1940 in Sredniy Kaban Lake. Both Kaban Lakes did not recover significantly until after the year 2000, when more substantial and new measures against Kaban Lakes pollution were initiated.

Historically, the Secchi depth was in the range of 1.5-2.2 $\mathrm{m}$ in both of the Kaban lakes. Sredniy Kaban Lake has largely recovered since 2010 when a major restoration was done on the Sredniy Kaban lake, but the Nizhniy Kaban Lake is still quite strongly polluted. More measures are required for that lake to recover properly.

\section{Discussion}

\subsection{Lack of Field Data}

Data from the system is only available at the very end of the study period (Table 2), and only as single values sampled randomly throughout the year. For such an expensive and large project, the biological and chemical monitoring has been inadequate for proper evaluation of success with the measures. The lack of data was a challenge in this project. This study was limited in success and applicability by the scarcity of data on the Kaban Lakes chemical and ecological state. We found few actual measurements and very few published data on the Kaban lake system, despite putting in a large effort into the data search. We searched for publications, local university research

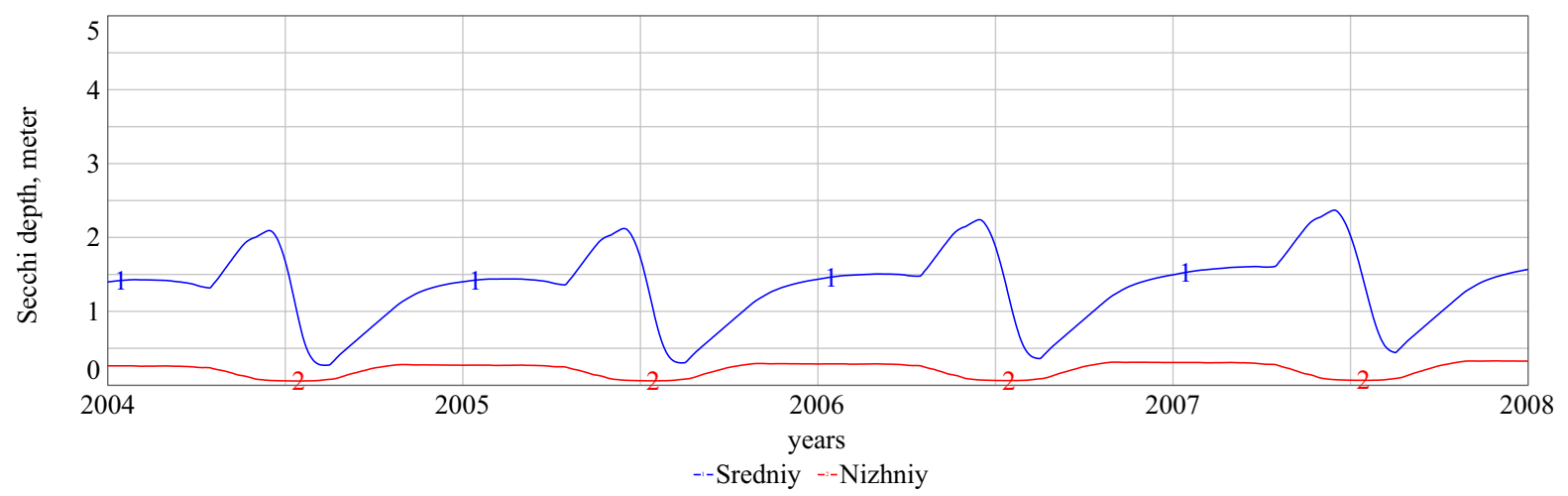

Fig. 27 Short-term variations in secchi depth in the Nizhniy and Sredniy Kaban Lakes according to the simulations for the years 2004 to 2008. It can be seen that the lakes clear up in the winter and become turbid during the warm season. Adopted from Fig. 26 
reports and made a number of inquiries to local municipal authorities. We made several interviews with colleagues in Kazan University. The final data harvest in total was slim.

\subsection{Using the Model for Measures Evaluation}

We used the KLIAM model and experimented with reducing phosphorus and nitrogen inputs to the Kaban Lakes to different extent. It is visible in the runs that reducing the phosphorus Kaban lake inputs strongly has a very strong effect on improving the status of the Kaban Lakes in terms of Secchi depth and lower plankton concentrations. This can be seen in Figs. 22 and 23 after year 2020 when we reduce phosphorus in the inflow. This has been shown elsewhere to be the most efficient long-term solution in other comparable systems (Sverdrup et al., 1991, Barkman \& Sverdrup, 1994, Barkman et al., 1994).

\subsection{Uncertainties}

The uncertainties in the model simulations come primarily from uncertainty in the data on system characteristics, hydrology and the lack of any timeseries for validation. This type of models has been applied in many other lakes and is known to perform well when the data availability is plentiful and accurate (Chapra \& Reckhow, 1983, Sverdrup et al., 1991, Jørgensen et al., 1990, Barkman \& Sverdrup, 1994, Barkman et al., 1994). Thus, the magnitude of the uncertainties involved cannot be estimated at the moment.

\subsection{Future Work}

Future studies are needed that will conduct sampling and create time series for hydrology, chemistry and biology in the Kaban Lakes system. Following that, the model should be reparameterized, validated on lake chemistry and biology time series of observations. Then, the model should be used for designing pollution mitigation and potential restoration as stateof-the-art outlined by Chapra and Reckhow (1983) in their handbook on the subject.

A next stage model for the Kaban Lakes is to enlarge the model with a more elaborate sediment dynamics model and dividing the Kaban Lakes into epilimnion and hypolimnion. This has been done and is under testing at present. This made the simulation outputs much more complex, but produced basically the same type of dynamics. If fish population management and fish species stocks manipulations are considered as alternative or additional measures, then a more elaborate ecosystem model will be required as was done by Sverdrup et al. (1991) for Lake Ringsjön in Southern Sweden or at Finjasjön, also Southern Sweden (Barkman et al., 1994a, Barkman et al., 1994). Before we can progress with this study, much better data than what is available today for the lake system will be required. Funding of a proper Kaban Lakes monitoring system and a dedicated effort is required. This elaborated model will be the subject of a future publication.

\section{Conclusions}

The test with the model shows that it describes the general historical development of the lakes quite well. The model can thus be used for investigating further improvements that can be planned for the lake system. We may summarize the findings:

1. The model explains why the Kaban Lakes are still polluted, and our results are consistent with what others have found for similar lake systems in Europe and North America.

2. The lack of field observations measurements on Kaban lakes chemical and ecological state was a limiting factor for this type of study

3. The model used is a state-of-the-art model for lakes polluted by phosphorus, and as such is transferrable to other similar lakes in the region.

4. State-of-the-art (Chapra \& Reckhow, 1983) eutrophic lake restoration uses this type of simulation model to back-check proposed measures for restoring the lakes, to ensure that the desired outcomes are really achieved, and well as to give an estimate for how long this would take. This model was designed for such a purpose for the Kaban Lakes.

5. Kazan University staff has the competence and modelling skills for assisting the restoration efforts for the Kaban Lakes system in the future, but better lake data will be needed.

The lakes are still eutrophic, despite large efforts already done to clean them up. They have moved 
from heavily eutrophic and severely polluted to moderately polluted and moderately eutrophic lakes, as we have been able to see. This is still visually visible at a visit to any of the Kaban Lakes in July of 2019. The improvements are very good and applaudable as a success, but more is needed to restore fully the Kaban Lakes to a state similar to their natural state. The Kaban Lakes and the restored areas around the lakes are very attractive areas for recreational purposes in Kazan city, and further improvements would be very desirable for the population. The Integrated Kaban Lakes Assessment Model (KLIAM) may be used as a tool for assisting the management of the Kaban lake area development in the future.

Author contribution All authors contributed to the study:

1. Associate Professor Dr. Liudmila L. Frolova, Genetics and Bioinformatics, Kazan Federal University, Kazan, Russia, Co-authored the composition of main text. Data and information collection, accessing local Russian reports, researchers and scientific literature and reading local databases available in Russian language only. Dr. Frolova did data collection in the Kaban Lakes and analyzed water samples and co-designing the KLIAM conceptualization.

2. Antoniy Elias Sverdrup, Master Student at Genetics and Bioinformatics, Kazan Federal University, Kazan, Russia, assisted with STELLA Architect programming and doing many of the KLIAM simulation runs.

3. Professor Dr. Harald Ulrik Sverdrup, Institute of Gamification and Interactive Simulations, Inland University of Applied Science, Hamar, Norway. Dr. Sverdrup was the main text and developing the modelling principles as CLDs in cooperation with the other authors (Group modelling). KLIAM conceptualization and programming in the STELLA Architect programming environment.

All authors contributed in the manuscript review and revision process.

Funding Open access funding provided by Inland Norway University Of Applied Sciences.

\section{Declarations}

Conflict of interest The authors declare that there is no conflict of interest involved with any of the aspects of the restoration of the Kaban Lakes. Two of the authors are citizens of Kazan and do enjoy the transformation of the Kaban Lakes into a beautiful recreational area for the Kazan city population, and would as interested citizens be happy to contribute to the positive development and nature protection of the Kaban Lakes.

Open Access This article is licensed under a Creative Commons Attribution 4.0 International License, which permits use, sharing, adaptation, distribution and reproduction in any medium or format, as long as you give appropriate credit to the original author(s) and the source, provide a link to the Creative Commons licence, and indicate if changes were made. The images or other third party material in this article are included in the article's Creative Commons licence, unless indicated otherwise in a credit line to the material. If material is not included in the article's Creative Commons licence and your intended use is not permitted by statutory regulation or exceeds the permitted use, you will need to obtain permission directly from the copyright holder. To view a copy of this licence, visit http://creativecommons.org/licenses/by/4.0/.

\section{References}

Albin, S., (1997). Building a system dynamics model; Part 1; Conceptualization. MIT System Dynamics Education Project (J. Forrester (Ed)). MIT, Boston. pp 34. https:// ocw.mit.edu/courses/sloan-school-of-management/15988-system-dynamics-self-study-fall-1998-spring-1999/ readings/building.pdf. Accessed May 2018.

Barkman, A., \& Sverdrup, H. U. (1994). Biomanipulation as a tool for mitigating eutrophication. Modelling the case study lake Finjasjön in southern Sweden. In: S. Jörgensen (Ed) Proceedings of the International Symposium on Ecosystems Manipulation p 234-255. Windermere, England.

Barkman, A., Sverdrup, H. U., \& Hamrin, H. (1994). Biomanipulation as a tool for mitigating eutrophication. Modelling the case study of Lake Finjasjön in Southern Sweden. In: Jenkins, A., Ferrier, B., Kirby, C., Lake Management p 286-288.

Baron, J. S., Bowman, W. D., Sverdrup, H. U., Driscoll, C. T., Stoddard, J. T., \& Hartman, M. D. (2009) Acidification and eutrophication of temperate North American and European ecosystems from atmospheric deposition. IOP Conference Series Earth and Environmental Science, 6, (46).

Chapra, S. C. \& Reckhow, K. H. (1983). Engineering approaches for lake management-Volume I. Prentice-Hall.

Derevenskaya, O. Y., Mingazova, N. M., Pavlova, L. R. (2015). Lake water quality of Kazan city (Russia) Kaban Lake in the anthropogenic pollution conditions and improving actions implementation. International Journal of Applied Engineering Research, 10, 44682-44687.

Dunaev, I. I. (1833). Results of chemical analysis of Volga and Kaban water. Zavolzhsky Ant, 3, 1149.

Filtzer, D. (2008). Poisoning the Proletariat: Urban water supply and river pollution in Russia's industrial regions during Late Stalinism, 1945-1953. Acta Slavica Iaponica, 26, 85-108.

Frolova, L. L., Sverdrup, A. E., \& Sverdrup, H. U. (2020). Using the Kaban Lakes Integrated Assessment Model for investigating potential levels of antibiotic pollution of the Nizhniy Kaban and Sredniy Kaban Lakes. Water, Air and Soil Pollution. Open Access Publication, 231, 430:1-1. https://doi.org/10.1007/s11270-020-04756-y

Forrester, J. W. (1961). Industrial dynamics. Pegasus Communications.

Forrester, J. W. (1969). Urban dynamics. Pegasus Communications.

Forrester, J. W. (1971). World dynamics. Pegasus Communications, Waltham MA. 
Glinsky, G. N. (1874). Observations on periodical changes of non-volatile organic compounds dissolved in the water of Lake Kaban. Internal report from Kazan University.

Haraldsson, H. (2004). Introduction to systems thinking and causal loop diagrams. Reports in Ecology and Environmental Engineering 1:2004 (5th ed.). Lund University.

Haraldsson, H., \& Sverdrup, H. (2005). On aspects of systems analysis and dynamics workflow. Proceedings of the systems dynamics society. International Conference on Systems Dynamics, Boston, USA, pp 10. http://www. systemdynamics.org/conferences/2005/proceed/papers/ HARAL310.pdf. Created by author 2004.

Haraldsson, H., Sverdrup, H., Belyazid, S., Holmqvist, J., \& Gramstad, R. C. J. (2008). The tyranny of small steps: A reoccurring behaviour in management. Systems Research and Behavioral Science, 25, 25-43.

Håkanson, L., \& Boulion, V. V. (2003). A general dynamic model to predict biomass and production of phytoplankton in lakes. Ecological Modelling, 165, 285-301.

Håkanson, L., \& Peters, R. H. (1995). Predictive limnology. Methods for predictive modelling. Amsterdam: SPB Academic Publishing, pp 464.

Håkanson, L., Malmaeus, J. M., Bodemar, U., \& Gerhardt, V. (2003). Coefficients of variation for chlorophyll, green algae, diatoms, cryptophytes and blue-greens in rivers as a basis for predictive modelling and aquatic management. Ecological Modeling, 169, 179-196.

Håkanson, L., Blenckner, T., Bryhn, A. C., \& Hellström, S. S. (2005). The influence of calcium on the chlorophyll-phosphorus relationship and lake Secchi depths. Hydrobiologia, 537, 111-123.

Håkanson, L., Bryhn, A. C., \& Hytteborn, J. K. (2007). On the issue of limiting nutrient and predictions of cyanobacteria in aquatic systems. Science of the Total Environment, 379, 89-108.

Ineson, P., Coward, C., Sverdrup, H., \& Benham, D. (1996). Nitrogen critical loads; Denitrification. Printed by the Institute of Terrestrial Ecology, Grange-over-Sands, Cumbria. Final Report to the Her Royal Majesty's British Ministry of the Environment.

ISEE Systems Inc, Hannover, New Hampshire, supplied the software used for the modelling: STELLA Architect 2.1. https://www.iseesystems.com/. Accessed May 2018.

Jørgensen, S. E., Kamp-Nielsen, L., \& Jørgensen, L. A. (1990). Examination of the generality of eutrophication models. Ecological Modelling, 32, 251-266.

Kalimullin, A. M. (2005). Environmental issues in context of industrial growth of Tatarstan Republic in the late $1960^{\text {th }}$ - early $1990^{\text {th }}$. Kazan University.

Kalimullin, A. M., \& Vinogradov, V. V. (2015). Ecological and sanitary problems of Kazan Province industrial development in the XIXth and early XXth centuries review of european studies. ISSN, 7, 1918-7173.

Kim, D. H. (1992). Toolbox: Guidelines for Drawing Causal Loop Diagrams. The Systems Thinker, 3, 5-6.

Klaus, K. K. (1839). Chemical decomposition of water of Kazan. Proceedings of Kazan University, 4, 82-107.

Krestovnikov, N. K. (1870). Industry and trade turnovers of Kazan. Internal report from Kazan University.
Kupidonov, V. G. (1890). Bacteriological exploring of water of the lake Kaban and Kazan plumbing: The dissertation for degree of doctor of medicine. University of Kazan.

Malmaeus, J. M., \& Håkanson, L. (2004). Development of a lake eutrophication model. Ecological Modelling, 171, 35-63.

Meadows, D. H., Meadows, D. L., Randers, J., \& Behrens, W. (1972). Limits to growth. Universe Books.

Meadows, D. L., Behrens, W. W., III., Meadows, D. H., Naill, R. F., Randers, J., \& Zahn, E. K. O. (1974). Dynamics of Growth in a Finite World. Wright-Allen Press Inc.

Meadows, D. H., Meadows, D. L., \& Randers, J. (1992). Beyond the limits: Confronting global collapse, envisioning a sustainable future. Chelsea Green Publishing Company.

Meadows, D. H., Randers, J., \& Meadows, D. (2005). Limits to growth. The 30 year update. Universe Press, New York.

Mingazova, N. N. (1999). The anthropogeneous change and restoration of small lakes ecosystems (on an example of the Middle Volga region). The dissertation on competition of a scientific degree of Dr.Sci.Biol. St. Petersburg University of Saint Petersburg, Russia.

Mingazova N., Derevenskaya O., Barieva E., \& Pavlova L. (2019). Restoration of low Kaban Lake (Kazan, Russia): 25-term experience of restoration and monitoring of ecological condition. pp 7. https://www.researchgate.net/publi cation/264890587

Modin-Edman, A. K., Öborn, I., \& Sverdrup, H. (2007). FARMFLOW-A dynamic model for phosphorus mass flow, simulating conventional and organic management of a Swedish dairy farm agricultural systems. Agricultural Systems, 94, 431-444.

Molot, L. A., \& Dillon, P. J. (1993). Nitrogen mass balances and denitrification rates in central Ontario lakes. Biogeochemistry, 20, 195-212.

Öborn, I., Modin-Edman, A. K., Bengtsson, H., Gustafson, G., Salomon, E., Nilsson, S. I., et al. (2005). A systems approach to assess farm-scale nutrient and trace element dynamics: A case study at the Öjebyn Dairy Farm. Ambio, 34, 298-308.

Persson, A., Barkman, A., Hansson, L. A., \& Sverdrup, H. (1999). Simulating the effects of biomanipulation on the food web of Lake Ringsjön. Hydrobiologia, 404, 131-144.

Ragnarsdottir, K. V., \& Sverdrup, H. (2011). Challenging the planetary boundaries II: Basic principles of an integrated for phosphorus supply dynamics and global population size. Applied Geochemistry, 26, S307-S310. https://doi. org/10.1016/j.apgeochem.2011.03.089

Roberts, N., Andersen, D. F., Deal, R. M., \& Shaffer, W. A. (1982). Introduction to Computer Simulation: A System Dynamics Approach Productivity Press.

Scheffer, M. (1990). Multiplicity of stable states in freshwater systems. Hydrobiologia, 200(201), 475-486.

Senge, P. (1990). The fifth discipline. The art and practice of the learning organisation. Century Business, New York.

Sverdrup, H., \& Barkman, A. (1995). Critical loads of nitrogen for marine ecosystems; suggesting and applying a simple method to the Bothnian Sea. In: M. Hornung, M. Sutton, R. Wilson, (Eds.), Mapping and modelling critical loads of nitrogen, a workshop report: 113-123. Proceedings of the Grange-Over-Sands Workshop by WGE LRTAP 
UN-ECE, October 24-26, 1994 Institute of Terrestrial Ecology, Edinburgh Research Station.

Sverdrup, H. U., Johnson, M. W., \& Fleming, R. H. (1942). The Oceans. Prentice-Hall.

Sverdrup, H., de Vries, W., \& Henriksen, A. (1990). Mapping critical loads. Nordic Council of Ministers Miljörapport 1990:15, Nord 1990:98.

Sverdrup, H. U., Warfvinge, P., \& Hamrin, S. (1991). A simple model for the eutrophication of Lake Ringsjön. Vatten, 47, 197-203.

Sverdrup, H. U. (Ed.), Haraldsson, H., Olafsdottir, A. H., Belyazid, S. (2018). System thinking, system analysis and system dynamics: Find out how the world works and then simulate what would happen. $3^{\text {rd }}$ revised edition. Háskolaprent Reykjavik. pp 310.

Sverdrup, H. U., Frolova, L. L., \& Sverdrup, A. E. (2020). Using a system dynamics model for investigating potential levels of antibiotics pollution in the Volga River. Water Air and Soil Pollution, 231, 173. https://doi.org/10.1007/ s11270-020-04526-w. Open access publication.
Sverdrup, A. E., Frolova, L. L., \& Sverdrup, H. S. (2022). A simple model for the hydrological dynamics of the Nizhniy and Sredniy Kaban Lakes. Draft manuscript to be submitted to journal during 2022.

Vishlenkova, E. A. (2005). Don't drink water from Kaban! Environmental crisis at $19^{\text {th }}$ century Kazan. Native Land, 8, 94-96.

Warfvinge, P., Sverdrup, H., \& Rosen, K. (1992) Calculating critical loads for $\mathrm{N}$ to forest soils. In: Grennfelt P. I. and Lövblad G., (Eds) Critical Loads and Levels for Nitrogen, 403-417. Nordic Council of Ministers. Nord, 1992, 41.

Publisher's note Springer Nature remains neutral with regard to jurisdictional claims in published maps and institutional affiliations. 